\title{
M2 macrophage-derived extracellular vesicles facilitate CD8+T cell exhaustion in hepatocellular carcinoma via the miR-21-5p/ YOD1/YAP/ $\beta$-catenin pathway
}

Jian $\mathrm{Pu}^{1,2,5,6}$, Zuoming $\mathrm{Xu}^{1,5,6}$, Jiahui Nian ${ }^{3}$, Quan Fang ${ }^{3}$, Meng Yang ${ }^{3}$, Youguan Huang ${ }^{3}$, Wenchuan $\mathrm{Li}^{1}$, Bin Ge ${ }^{1}$, Jianchu Wang ${ }^{1,2}$ and Huamei Wei ${ }^{4 凶}$

(c) The Author(s) 2021

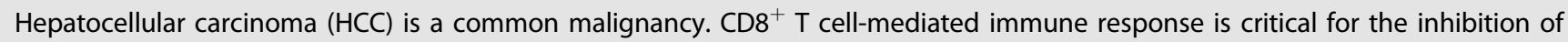
HCC progression. M2 macrophages participate in HCC progression. This study set out to investigate the effect of M2 macrophagederived extracellular vesicles (EVs) on $\mathrm{CD}^{+} \mathrm{T}$ cell exhaustion in HCC. M2 macrophage-derived EVs were isolated and identified. The murine model of primary $\mathrm{HCC}$ was established through $\mathrm{DEN} / \mathrm{CCl}_{4}$ induction, and model mice were injected with EVs. Peripheral blood mononuclear cells (PBMCs) were isolated from the mouse liver and $\mathrm{CD}^{+} \mathrm{T}$ cells were sorted. The expressions of immune checkpoint inhibitory receptors and effector cytokines on $\mathrm{CD}^{+} \mathrm{T}$ cells were detected, followed by the evaluation of $\mathrm{CD} 8^{+} \mathrm{T}$ cell proliferation and killing function. miR-21-5p expression in $M 2$ macrophage-derived EVs was detected. The binding relationship between miR-21-5p and YOD1 was verified. The activation of the YAP/ $\beta$-catenin pathway was detected. Consequently, M2 macrophage-derived EVs promoted $\mathrm{CD}^{+} \mathrm{T}$ cell exhaustion in HCC mice. miR-21-5p expression was upregulated in $\mathrm{M} 2$ macrophage-derived EVs, and EVs carried miR-21-5p into HCC tissues. miR-21-5p targeted YOD1. Inhibition of miR-21-5p or overexpression of YOD1 annulled the promoting effect of EVs on CD8 ${ }^{+} \mathrm{T}$ cell exhaustion. YOD1 inactivated the YAP/ $\beta$-catenin pathway. In conclusion, M2 macrophage-derived EVs facilitated CD8 ${ }^{+} \mathrm{T}$ cell exhaustion via the miR-21-5p/YOD1/YAP/ $\beta-$ catenin axis. This study may confer novel insights into the immunotherapy of HCC.

Cell Death Discovery (2021)7:182; https://doi.org/10.1038/s41420-021-00556-3

\section{INTRODUCTION}

Primary hepatocellular carcinoma (HCC) is an aggressive malignancy that constitutes the primary cause of cancer-related death [1]. The acknowledged risk factors for HCC include chronic HBV or HCV infection, metabolic liver disorders, and liver cirrhosis [2]. The microenvironment of highly immune HCC makes immunotherapy a promising target for HCC [3]. Tumor-induced immunosuppression and immune evasion facilitate cancer progression and impede the efficacy of immunotherapy $[4,5]$. Indeed, a large number of immunotherapies have been designed for HCC patients to enhance tumor-specific immune response, but the clinical benefits are limited [6]. Despite certain genetic and epigenetic alterations that have been observed in HCC cells, the exact pathogenesis of HCC is not elucidated [7]. Surgical resection and liver transplant are available for the HCC patients at the early stage; however, the overall survival rate is still limited due to the high recurrence rate and low qualified rate of surgery and transplant [8]. A systematic review of tumor-infiltrating lymphocytes demonstrates that the major reasons for tumor escape in the immune system include the dysfunction of $\mathrm{CD}^{+} \mathrm{T}$ cells and the presence of excessive suppressor T cells [9]. Under the condition of prolonged antigen exposure, the tumor-specific effector $\mathrm{CD} 8^{+} \mathrm{T}$ may differentiate into a stage called $\mathrm{T}$ cell exhaustion [10]. $\mathrm{CD} 8^{+} \mathrm{T}$ cell exhaustion is often concerned with invalid infection control and the weakened anti-tumor effect [11]. Hence, targeting CD8 ${ }^{+}$ $T$ cells is the main direction of immunotherapy for HCC.

Tumor microenvironment (TME) is composed of various cell types such as endothelial cells, fibroblasts, and immune cells, and extracellular components such as growth factors, proteolytic enzymes, extracellular matrix, and cytokines [12]. All cellular and non-cellular components of TME generate a neoplastic niche where tumor cells proliferate rapidly and escape the attack of the host defense system [13]. Macrophages are the most prominent immune cells in TME. Macrophages are a class of leukocytes with antigen presentation ability, which actively participate in tissue remodeling, phagocytosis, and clearance of foreign substances and cell debris [14]. Macrophages have a variety of functions related to cancer progression; they contribute to the escape of tumor cells and hinder the anti-tumor immune mechanism and response [15]. Macrophages are categorized into the classically activated (M1) and the

\footnotetext{
${ }^{1}$ Department of Pathology, Affiliated Hospital of Youjiang Medical University for Nationalities, Guangxi Zhuang, China. ${ }^{2}$ Clinic Medicine Research Center of Hepatobiliary Diseases, Guangxi Zhuang, China. ${ }^{3}$ Department of Hepatobiliary Surgery, Affiliated Hospital of Youjiang Medical University for Nationalities, Guangxi Zhuang, China. ${ }^{4}$ Graduate College of Youjiang Medical University for Nationalities, Guangxi Zhuang, China. ${ }^{5}$ These authors contributed equally: Jian Pu, Zuoming Xu. ${ }^{6}$ These authors are co-first authors: Jian Pu, Zuoming Xu. ${ }^{\bowtie}$ email: huamw0910@163.com

Edited by I. Amelio
}

Received: 29 March 2021 Revised: 26 May 2021 Accepted: 13 June 2021

Published online: 16 July 2021 
alternatively activated (M2) macrophage according to the polarization status; M1 macrophages exert tumoricidal effects while M2 macrophages facilitate tumorigenesis [16]. In TME, M2 macrophages have tumor-promoting activities by facilitating HCC cell proliferation, migration, angiogenesis, and immunosuppression, and additionally, M2 macrophages are associated with the unfavorable outcome of HCC [17]. Extracellular vesicles (EVs) are bioactive molecular shuttles packaged by proteins, lipids, and nucleic acids, which modulate TME by interacting with adjacent cells [18]. M2 macrophage-derived EVs can lead to the progression of colon cancer [19] and gastric cancer [20]. However, the effect of M2 macrophage-derived EVs on $\mathrm{CD}^{+} \mathrm{T}$ cell exhaustion in $\mathrm{HCC}$ remains unknown. This study herein investigated the effect of $M 2$ macrophage-derived EVs on $\mathrm{CD}^{+} \mathrm{T}$ cell exhaustion in $\mathrm{HCC}$, which shall confer novel insights into the immunotherapy of HCC.

\section{MATERIALS AND METHODS \\ Ethics statement}

This study was approved by the Ethical Committee of Affiliated Hospital of Youjiang Medical College for Nationalities. Adequate laboratory procedures were made to minimize the pain of mice, such as heating pads, disinfection, and fluid replacement with normal saline.

\section{Isolation and identification of mouse macrophage}

Female C57BL/6 mice (aged 6-8 weeks and weighing 20-24 g) were purchased from DOSSY Experimental Animals Co., Ltd (Chengdu, Sichuan, China) [SCXK (Sichuan) 2019-028] and euthanized by intraperitoneal injection of $\geq 100 \mathrm{mg} / \mathrm{kg}$ pentobarbital sodium. Two femurs of each mouse were separated and soaked in $75 \%$ alcohol for $5 \mathrm{~min}$. The femurs were washed twice with sterile phosphate-buffered saline (PBS). The two ends of the femurs were cut off, and then the bone marrow in the femurs was repeatedly rinsed with Dulbecco's modified Eagle's medium (DMEM) by a syringe until the femurs turned white. The rinsed bone marrow cell suspension was collected and centrifuged at $150 \mathrm{~g}$ for $5 \mathrm{~min}$ to remove the supernatant. The cells were resuspended in DMEM. The isolated bone marrow cells were seeded on a $10-\mathrm{cm}$ cell culture plate and cultured in DMEM/F12 complete medium containing $10 \%$ fetal bovine serum (FBS). Macrophage colony-stimulating factor (M-CSF) was added to the medium till the concentration reached $100 \mathrm{U} / \mathrm{mL}$. The medium was refreshed every 3 days and supplemented with M-CSF. The non-adherent cells were removed and bone marrow-derived macrophages were obtained after 7 days.

Bone marrow-derived macrophages were harvested, suspended in $5 \mu \mathrm{L}$ PBS and dripped on the slides. After drying, the macrophages were stained with Wright's dye for $10 \mathrm{~min}$, washed with running water, and observed under the microscope. Then, $1 \times 10^{6}$ cells were collected and resuspended for flow cytometry. The macrophages were cultured with two fluorescent antibodies and homologous control on ice for 30 min, washed with fluorescence-activated cell sorting buffer, and fixed in $10 \%$ formalin. The positive rate of antigen was detected using flow cytometer. The antibodies used were CD68 (1:100, ab31630, Abcam, Cambridge, MA, USA) and CD163 (1:60, ab182422, Abcam).

\section{Induction and identification of M2 macrophage}

The mouse bone marrow-derived macrophages were seeded into the $6 / 12 / 24$ well plates and cultured in DMEM/F12 complete medium containing $10 \%$ FBS. After cell adherence to the wall, the cells were treated with $20 \mathrm{ng} / \mathrm{mL}$ IL-4 (Sigma-Aldrich, Merck KGaA, Darmstadt, Germany) for $24 \mathrm{~h}$ [21]. The expressions of typical polarized molecules CCL22 and PPARy in M2 macrophages were detected using RT-qPCR. The positive rates of CD163 and CD86 antigens were detected using flow cytometry.
Isolation and identification of M2 macrophage-derived EVs EVs in FBS were removed after centrifugation at $100,000 \times g$ for 10 min. When M2 macrophages reached about $80 \%$ confluence, the supernatant was removed. Then $\mathrm{M} 2$ macrophages were added with $10 \%$ EVs-free FBS and cultured at $37^{\circ} \mathrm{C}$ for $48 \mathrm{~h}$. M2 macrophage-derived EVs were extracted by ultracentrifugation [22]: the supernatant was collected when the medium was refreshed, and then centrifuged at $4{ }^{\circ} \mathrm{C}$ and $500 \mathrm{~g}$ for $10 \mathrm{~min}$ and at $12000 \times g$ for $20 \mathrm{~min}$. The supernatant was filtered through a $0.22 \mu \mathrm{m}$ filter membrane and centrifuged at $100,000 \times g$ for $2 \mathrm{~h}$. The precipitates were resuspended in PBS, ultra-centrifuged again for $2 \mathrm{~h}$, and stored at $-80^{\circ} \mathrm{C}$ after PBS resuspension. The EVs derived from the isolated M2 macrophages were identified by the following methods: the morphology of isolated EVs was observed under the transmission electron microscope (TEM); the size distribution of the EVs was analyzed using Nanoparticle tracking analysis (NTA); the expressions of CD9, CD63, and CD81 on the surface of EVs were verified using Western blotting, with the supernatant of M2 macrophages added with GW4869 as negative control (NC). The identified EVs were lysed, and the total protein content was determined using a bicinchoninic acid (BCA) assay kit. The protein content was used as the standard for EVs.

EVs were assigned into 4 groups: NC group (supernatant of M2 macrophages added with GW4869), EVs group, EVs-NC group (EVs were isolated from inhibitor NC-transfected M2 macrophages), and EVs-inhi group (EVs were isolated from miR-21-5p inhibitortransfected M2 macrophages). miR-21-5p inhibitor and inhibitor NC were provided by GenePharma (Shanghai, China).

\section{Establishment of the murine model of primary HCC}

Two weeks old C57BL/6 mice were intraperitoneally injected with diethylnitrosamine (DEN; $25 \mathrm{mg} / \mathrm{kg}$ ) once a week for 3 consecutive weeks. When the mice were 5 weeks old, $\mathrm{CCl}_{4}(0.5 \mu \mathrm{L} / \mathrm{g})$ was intraperitoneally injected once a week for 12 consecutive weeks. At the $15^{\text {th }}$ and $40^{\text {th }}$ weeks after induction, the liver of mice was detected.

The experimental mice were assigned into 6 groups: control group, HCC group, HCC + NC group (mice were injected with NC via tail vein), $\mathrm{HCC}+\mathrm{EVs}$ group (mice were injected with EVs via tail vein), HCC + EVs-NC group (mice were injected with EVs-NC via tail vein), $\mathrm{HCC}+\mathrm{EVs}$-inhi group (mice were injected with EVs-inhi via tail vein). According to the protein content of EVs, the mice were injected with $20 \mu \mathrm{g}$ EVs every day for 7-20 days. All mice were euthanized by intraperitoneal injection of $\geq 100 \mathrm{mg} / \mathrm{kg}$ pentobarbital sodium, followed by tissue collection. In this study, 108 mice were used for the establishment of the murine model of primary $\mathrm{HCC}$, with 18 mice in each group. Among them, 6 mice were used for tumorigenesis observation, 6 mice were used for hematoxylin and eosin ( $\mathrm{HE}$ ) staining to observe the histopathological changes and immunohistochemistry to detect the number of $\mathrm{CD}^{+} \mathrm{T}$ cells, and the remaining 6 mice were used for the extraction of peripheral blood mononuclear cells (PBMCs) and determination of miR-21-5p and YOD1 mRNA expression.

Hematoxylin-eosin (HE) staining. The liver tissues of mice were fixed with $4 \%$ formaldehyde for $6 \mathrm{~h}$ and embedded in paraffin. The paraffin-embedded liver tissues were cut into $3 \mu \mathrm{m}$ sections, baked overnight at $60^{\circ} \mathrm{C}$, and dewaxed twice with xylene I (14936-97-1, Shanghai Research Biological Technology Co., Ltd., Shanghai, China) and xylene II (523-67-1, Shanghai Yuduo Biotechnology Co., Ltd., Shanghai, China). The sections were soaked in $100 \%, 100 \%, 95 \%$, $80 \%$, and $70 \%$ ethanol for $5 \mathrm{~min}$ and then put into distilled water. Next, the sections were stained with hematoxylin (474-07-7, Qingdao Jisskang Biotechnology Co., Ltd., Qingdao, China) for $10 \mathrm{~min}$ and washed with running water for 15 min to turn sections blue. Then, the sections were stained with eosin (RY0648, Qingdao Jisskang Biotechnology co., Ltd.) for $30 \mathrm{~s}$, washed with double-distilled water, dehydrated with alcohol, cleared with xylene, sealed with neutral 
balsam, and analyzed using a morphological image analysis system (JD801, Jeda Technology Co. Ltd., Nanjing, China).

Immunohistochemistry (IHC). Immunohistochemical assay was performed using diaminobenzidine (DAB) IHC kit (GS4974, Biolab, Beijing, China) to detect the number of $\mathrm{CD} 8^{+} \mathrm{T}$ cells in liver tissues. The liver tissues of HCC mice were baked at $45^{\circ} \mathrm{C}$ for $3 \mathrm{~h}$. After dewaxing and hydration, the sections were added with $3 \% \mathrm{H}_{2} \mathrm{O}_{2}$ and placed at room temperature for $10 \mathrm{~min}$ to eliminate the activity of endogenous peroxidase. Following 3 times of PBST washing, the sections were put into citrate buffer for microwave antigen repair. Next, the solution was heated to boiling and cooled naturally (5-10 min). After 3 times of repair, it was cooled to room temperature. Then, the sections were incubated with goat serum at $37^{\circ} \mathrm{C}$ for $1 \mathrm{~h}$, and then the blocking buffer was removed. Next, the sections were incubated with the primary antibody CD8 (1:2000, ab217344, Abcam) at $4{ }^{\circ} \mathrm{C}$ overnight. The next day, the sections were rewarmed to room temperature, washed with PBST 3 times, and incubated with biotinylated secondary antibody working solution at $37^{\circ} \mathrm{C}$ for $15 \mathrm{~min}$. The sections were washed 3 times with PBST to wash out the unbound antibody and incubated with HPR-labeled streptavidin working solution at $37^{\circ} \mathrm{C}$ for $15 \mathrm{~min}$. Following 3 times of PBST washing, the sections were incubated with DAB chromogenic solution for $5 \mathrm{~min}$ at room temperature, counterstained with hematoxylin, and then dehydrated, cleared, and sealed.

\section{Extraction of mouse liver PBMCs}

The mice were euthanized, and the liver was collected and cut up and ground into homogenate by adding PBS, and then transferred to a $50 \mathrm{~mL}$ centrifuge tube for 1-min centrifugation at $150 \mathrm{~g}$ to remove the supernatant. After centrifugation at $400 \mathrm{~g}$ for $5 \mathrm{~min}$, the supernatant was removed and the cell precipitate was resuspended using PBS. After centrifugation at $400 \mathrm{~g}$ for $5 \mathrm{~min}$, the supernatant was discarded and the sample was washed with PBS once. The samples were added with $5 \mathrm{~mL} 40 \%$ percoll working solution for resuspension and centrifuged at $800 \mathrm{~g}$ for $25 \mathrm{~min}$. The upper two layers were rapidly isolated and the lower precipitate was collected. Then, $3 \mathrm{~mL}$ red blood cell lysate was added to resuspend the cells. The cells were lysed at $4^{\circ} \mathrm{C}$ for $10 \mathrm{~min}$ and added with $20 \mathrm{~mL}$ PBS to terminate the lysis. The cells were centrifuged at $400 \mathrm{~g}$ for $5 \mathrm{~min}$ to remove the supernatant and resuspended in an appropriate amount of PBS. Afterwards, the cells were filtered through a 200-mesh screen and finally the liver PBMCs were obtained.

\section{$\mathrm{CDB}^{+} \mathbf{T}$ cell sorting and culture}

PBMCs prepared from liver tissues were filtered through a cell filter $(70 \mu \mathrm{m})$, added with the upper layer of Ficoll-Paque $(10 \mathrm{~mL})$, and centrifuged at $400 \mathrm{~g}$ and $20^{\circ} \mathrm{C}$ for $30 \mathrm{~min}$. After centrifugation, the cloud-like lymphocyte layer in the middle was further sorted using $\mathrm{CD}^{+}$magnetic beads. The cells that need to be analyzed using flow cytometer were pretreated. Fixable viability dye (FVD) was used to remove dead cells. The cell staining buffer containing $2 \%$ FBS and $2 \mathrm{mM}$ ethylene diamine tetraacetic acid was used for the detection of cell surface markers. The purity $(>95 \%)$ of sorted cells was determined using flow cytometry. The sorted $\mathrm{CD}^{+}$ T cells were stimulated using anti-CD3 $(5 \mu \mathrm{g} / \mathrm{mL})$ and CD28 $(2 \mu \mathrm{g} /$ $\mathrm{mL}$ ) antibodies in vitro.

$\mathrm{CD}^{+} \mathrm{T}$ cells were assigned into 6 groups: blank group [partially exhausted $\mathrm{CD}^{+}{ }^{+}$cells (PD1 $1^{\text {int }} \mathrm{TIM}^{+}$) were sorted from mouse $\mathrm{HCC}$ infiltrating $\mathrm{CD}^{+} \mathrm{T}$ cells], EVs group $\left(\mathrm{CD} 8^{+} \mathrm{T}\right.$ cells were treated with $50 \mu \mathrm{g}$ EVs for $6 \mathrm{~h}$ ), EVs-NC group (CD8 ${ }^{+} \mathrm{T}$ cells were treated with $50 \mu \mathrm{g}$ EVs-NC for $6 \mathrm{~h}$ ), EVs-inhi group (CD8 ${ }^{+} \mathrm{T}$ cells were treated with $50 \mu \mathrm{g}$ EVs-inhi for $6 \mathrm{~h}$ ), oe-YOD1 + EVs group $\left(C D 8{ }^{+} \mathrm{T}\right.$ cells were transfected with pCDNA-YOD1 for $24 \mathrm{~h}$ and then treated with $50 \mu \mathrm{g}$ EVs for $6 \mathrm{~h}$ ) and oe-NC + EVs group (CD8 ${ }^{+}$ $\mathrm{T}$ cells were transfected with pcDNA-NC for $24 \mathrm{~h}$ and then treated with $50 \mu \mathrm{g}$ EVs for $6 \mathrm{~h}$ ).

\section{Flow cytometry}

The total number and concentration of sorted $\mathrm{CD} 8^{+} \mathrm{T}$ cells were calculated using a cell counter. For cell surface staining, the cells were resuspended in 2\% PBS, cultured with primary antibodies [PD1 (17-9981-82, eBioscience, San Diego, CA, USA), TIM3 (119717, BioLegend, San Diego, CA, USA), IFN- $\gamma$ (564336, BD Bioscience), IL-2 (562483, BD Bioscience) and TNF-a (257321, eBioscience)] on ice for $30 \mathrm{~min}$ and washed twice with PBS, followed by detection on flow cytometer. For intracellular staining, the cells were fixed, permeabilized, and cultured with fluorescence-labeled secondary antibody for $30 \mathrm{~min}$, and finally detected on flow cytometer. For the detection of cytokines, $\mathrm{CD}^{+} \mathrm{T}$ cells were stimulated by $50 \mathrm{ng} / \mathrm{mL}$ phorbol myristate acetate (PMA) (Enzo, NY, USA), $1 \mu \mathrm{g} / \mathrm{mL}$ ionomycin (Enzo), and $10 \mu \mathrm{g} / \mathrm{mL}$ brefeldin $A$ (Enzo) at $37^{\circ} \mathrm{C}$ for $6 \mathrm{~h}$ and then treated with the corresponding dyeing. The dead cells were labeled with Fixable Viability Stain 620 reagent (BD Biosciences) and deleted during flow cytometry. FACS Aria II Cell Sorter (BD Biosciences) was used for flow cytometry and FlowJo software (TreeStar, Ashland, USA) was used for data analysis.

\section{Detection of $\mathrm{CDB}^{+} \mathbf{T}$ cell killing}

The sorted $\mathrm{CD}^{+}{ }^{+}$cells were activated using anti-CD3 $(5 \mu \mathrm{g} / \mathrm{mL})$ and CD28 $(2 \mu \mathrm{g} / \mathrm{mL})$ for 3 days. Mouse hepatoma cell line Hepal-6 [Cell Bank of Chinese Academy of Sciences (Shanghai, China)] was labeled with carboxyfluorescein diacetate succinimidyl ester (CFSE) and then seeded on the 48 -well plates $\left(2 \times 10^{5}\right.$ cells/well). The activated $\mathrm{CD} 8^{+} \mathrm{T}$ cells were cultured with adherent hepatoma cells overnight at an effector-target ratio of 20:1. The cell mixture was collected and the dead cells were stained with 7AAD (A1310, Invitrogen Inc., Carlsbad, CA, USA) for $10 \mathrm{~min}$. The cell killing was measured using flow cytometry: killing efficiency $(\%)=\left(\% \mathrm{CFSE}^{+}\right.$ $\left.7 \mathrm{AAD}^{+}\right) /\left(\% \mathrm{CFSE}^{+}\right) \times 100$.

\section{Measurement of $\mathrm{CDB}^{+} \mathbf{T}$ cell proliferation}

The sorted $\mathrm{CD}^{+}{ }^{+}$cells were activated using anti-CD3 $(5 \mu \mathrm{g} / \mathrm{mL})$ and CD28 $(2 \mu \mathrm{g} / \mathrm{mL})$ antibodies for 3 days. $\mathrm{CD}^{+} \mathrm{T}$ cell proliferation was measured using flow cytometry.

\section{Uptake of EVs}

Antigen-specific $\mathrm{CD}^{+} \mathrm{T}$ cells were seeded onto the 24-well cell slides $\left(3 \times 10^{4}\right.$ cells/well). After cell adherence, the cells were cultured with PKH67 (Sigma-Aldrich)-labeled EVs $(80 \mathrm{~g} / \mathrm{mL}$ ) for 1 day. The slides were fixed in $4 \%$ paraformaldehyde for $20 \mathrm{~min}$, washed 3 times with PBS, stained with 4',6-diamidino-2-phenylindole for $1 \mathrm{~h}$, sealed with anti-fluorescence quenching agent, and photographed under the fluorescence microscope.

\section{Reverse transcription quantitative polymerase chain reaction (RT-qPCR)}

The total RNA was extracted using TRIzol reagent (Invitrogen) and reverse transcribed into cDNA using PrimeScript RT reagent kit (Takara, Dalian, China). The TaqMan primers and probes were all from TaKaRa (Kyoto, Japan). The ABI PRISM 7900 sequence detection system of SYBR Green II (TaKaRa) was used for quantitative PCR. The PCR procedures were as follows: predenaturation at $95^{\circ} \mathrm{C}$ for $5 \mathrm{~min}$, and 40 cycles of denaturation at $95^{\circ} \mathrm{C}$ for $15 \mathrm{~s}$, annealing at $60^{\circ} \mathrm{C}$ for $20 \mathrm{~s}$ and extension at $72{ }^{\circ} \mathrm{C}$ for $35 \mathrm{~s}$. GAPDH and U6 were used as the internal reference. The relative expression of genes was calculated using the $2^{-} \Delta \Delta C T$ method. The primer sequences (Sangon Biotech, Shanghai, China) are shown in Supplementary Table 1.

\section{Western blotting}

The liver homogenate and cells were lysed in enhanced radioimmunoprecipitation assay lysate containing protease inhibitor for $20 \mathrm{~min}$ and centrifuged at $4{ }^{\circ} \mathrm{C}$ for $20 \mathrm{~min}$ to collect the supernatant. The protein concentration in the supernatant was 
detected using the BCA protein quantitative kit (Boster Biological Technology Co., Ltd, Wuhan, Hubei, China). The proteins were separated by $10 \%$ SDS-PAGE and transferred onto polyvinylidene fluoride membranes. The membranes were blocked with $5 \%$ bovine serum albumin for $2 \mathrm{~h}$ to block nonspecific binding. Next, the membranes were incubated with the primary antibodies YAP1 (ab56701, Abcam) and $\beta$-catenin (ab32572, Abcam) at $4{ }^{\circ} \mathrm{C}$ overnight. Following tris-buffered saline-tween washing, the membranes were incubated with HRP-labeled secondary antibody for $1 \mathrm{~h}$ and developed with enhanced chemiluminescence reagent (Merck Millipore, Billerica, MA, USA). The gray level of each band was analyzed using Image Pro Plus 6.0 (Media Cybernetics, Bethesda, MA, USA), with $\beta$-actin (ab8226, Abcam) as an internal reference. The experiment was repeated three times.

\section{Bioinformatics analysis}

The target genes of miRNA were predicted through Starbase (http://starbase.sysu.edu.cn/), RNAInter database (http://www.rnasociety.org/rnainter/) and miRDB (http://www.mirdb.org/). The coexpression relationship of genes was searched through Coexpedia (http://www.coexpedia.org/), and the coexpression score was obtained to further screen the target genes.

\section{Statistical analysis}

Data analysis was introduced using the SPSS 21.0 (IBM Corp., Armonk, NY, USA) and GraphPad Prism 8.0 (GraphPad Software Inc., San Diego, CA, USA). Kolmogorov-Smirnov test was used to verify the normal distribution of continuous variables. Data are expressed as mean \pm standard deviation. The $t$-test was used for comparison between two groups. One-way analysis of variance (ANOVA) was employed for comparisons among multiple groups, followed by Tukey's multiple comparisons test. The value of $p<$ 0.05 indicated a significant difference.

\section{RESULTS \\ Isolation and identification of M2 macrophage and EVs}

Macrophages were obtained from the bone marrow of mice and stained with Wright after primary culture. Under the microscope, the morphology of macrophages was irregular, and the nuclei were in dark blue and inclined to one side, showing typical morphological characteristics of macrophages (Supplementary Fig. 1A). Flow cytometry showed that macrophage-specific molecular marker CD68 was positive (Supplementary Fig. 1B). M2 macrophages were prepared by IL-4 induction. M2 macrophages were significantly enlarged under the microscope, mainly presented as large round cells (Supplementary Fig. 1C). RT-qPCR showed that the mRNA expressions of CCL22 and PPARY in M2 macrophages were notably increased after induction (Supplementary Fig. 1D, E). Flow cytometry indicated that the number of $\mathrm{CD} 163^{+}$cells (M2 macrophages) was over $90 \%$, and the number of $\mathrm{CD}^{+} 6^{+}$cells (M1 macrophages) was little (Supplementary Fig. 1F), indicating that M2 macrophages were successfully induced and obtained. EVs were isolated from M2 macrophages by ultracentrifugation. Under the TEM, EVs were round or oval with uneven particles and were $60-160 \mathrm{~nm}$ in diameter, and the membrane-like structure was observed around the EVs (Supplementary Fig. 1G). NTA further confirmed the size and distribution of EVs. EVs were mainly distributed at about $100 \mathrm{~nm}$, and the concentration was $2.3 \times 10^{6}$ particles $/ \mathrm{mL}$ (Supplementary Fig. 1H). Western blotting demonstrated that CD9 and CD63 were enriched in the extracted EVs, while there was no significant expression of calnexin (Supplementary Fig. 11). Briefly, the M2 macrophage-derived EVs were successfully isolated.

\section{M2 macrophage-derived EVs promoted tumor progression and $\mathrm{CDB}^{+} \mathrm{T}$ cell exhaustion in mice with primary HCC} The murine model of primary $\mathrm{HCC}$ was established by $\mathrm{DEN} / \mathrm{CCl}_{4}$ induction to explore the role of M2 macrophage-derived EVs in HCC.
EVs were labeled with PKH67, and the green fluorescence could be observed in the liver tissues, indicating that EVs were transferred into the mouse liver via tail vein injection and absorbed by liver tissues (Fig. 1A). After 40 weeks of induction, the mice developed primary HCC, and obvious tumor nodules were observed on the surface of the liver. EV treatment promoted the tumorigenesis in mice, with a higher malignant degree of tumor (Fig. 1B). Immunohistochemistry showed that compared with that in healthy control mice, the number of infiltrating $\mathrm{CD} 8^{+} \mathrm{T}$ cells in $\mathrm{HCC}$ mice was significantly reduced, and EV treatment further reduced the number of infiltrating $\mathrm{CD}^{+} \mathrm{T}$ cells in HCC tissues (Fig. 1C). Then, PBMCs were isolated from the mouse liver and $\mathrm{CD}^{+} \mathrm{T}$ cells were sorted. The expressions of immune checkpoint inhibitory receptors (PD1 and TIM3) on CD8 ${ }^{+}$ cells and the production of effector cytokines (IFN- - , IL-2, and TNF-a) were detected using flow cytometry. Compared with healthy control mice, HCC mice showed notably enhanced levels of surface markers of $\mathrm{CD}^{+} \mathrm{T}$ cell exhaustion (all $p<0.01$; Fig. 1D) and reduced effector cytokines (all $p<0.01$; Fig. $1 \mathrm{E}$ ), suggesting that the infiltrating $\mathrm{CD}^{+}$ $\mathrm{T}$ cells in HCC mice were in a state of functional exhaustion. To further verify the functional exhaustion of $\mathrm{CD}^{+} \mathrm{T}$ cells in the liver, we labeled $\mathrm{CD}^{+}{ }^{+} \mathrm{T}$ cells with CFSE and stimulated them with anti-CD3/ CD28 antibodies for 3 days, and then detected their proliferation and killing function. Compared with that in control mice, the proliferation of $\mathrm{CDB}^{+} \mathrm{T}$ cells in HCC mice was notably decreased (Fig. 1F), and the ability to kill Hep1-6 cells was weakened (Fig. 1G). The addition of EVs further increased the expressions of surface markers of $\mathrm{CD}^{+} \mathrm{T}$ cell exhaustion, decreased the production of effector cytokines, and weakened the proliferation of $\mathrm{CD}^{+}{ }^{+}$cells and the ability to kill Hep1-6 cells. Altogether, M2 macrophage-derived EVs promoted $\mathrm{CD}^{+} \mathrm{T}$ cell exhaustion in mice with primary HCC.

\section{EVs carried miR-21-5p into the liver tissue of mice}

Lou et al. have analyzed the miRNA microarray GSE69580 of HBVrelated HCC and found that miR-21 is abnormally upregulated in HCC and plays a vital role in the prognosis of HCC [23]. ECORI PanCer database also demonstrated that miR-21-5p was highly expressed in HCC (Fig. 2A). Additionally, functional miR-21-5p in leukemic cell-derived EVs can be introduced into T cells to induce exhaustion phenotype [24]. miR-21-5p expression in $M 2$ macrophage-derived EVs was detected using RT-qPCR, and the results revealed that miR-21-5p expression in EVs was notably higher than that in GW4869-treated control ( $p<0.01$; Fig. 2B). Therefore, we speculated that M2 macrophage-derived EVs promoted the exhaustion of infiltrating $\mathrm{CD}^{+}{ }^{+} \mathrm{T}$ cells in HCC through miR-21-5p. Furthermore, RNase treatment had no significant effect on miR-21-5p expression in EVs, while miR-21$5 p$ expression was notably reduced in EVs after the combined treatment of RNase and EVs lysate (all $p<0.01$; Fig. 2B), indicating that miR-21-5p was encapsulated in EVs. miR-21-5p expression in M2 macrophages was significantly reduced after transfection with miR-21-5p inhibitor ( $p<0.01$; Fig. $2 \mathrm{C}$ ). Then, EVs were isolated from miR-21-5p inhibitor-transfected M2 macrophages, and miR21-5p expression in EVs-inhi was also notably decreased $(p<0.01$; Fig. 2D). HCC mice were treated with EVs-inhi, and miR-21-5p expression in liver tissues of mice was decreased (all $p<0.05$; Fig. 2E), and EVs-inhi treatment partially reversed the promoting effect of EVs on $\mathrm{CD}^{+} \mathrm{T}$ cell exhaustion in primary $\mathrm{HCC}$ mice (Fig. 2F-I). Briefly, EVs facilitated $\mathrm{CD}^{+} \mathrm{T}$ cell exhaustion in primary HCC mice by carrying miR-21-5p.

\section{EVs facilitated $\mathrm{CDB}^{+} \mathrm{T}$ cell exhaustion}

To further determine the effect of EVs on $\mathrm{CD}^{+}$cell exhaustion, the infiltrating $\mathrm{CD}^{+} \mathrm{T}$ cells sorted from $\mathrm{HCC}$ mice were divided into three groups: normal $\mathrm{CD}^{+}{ }^{+} \mathrm{T}$ cells (PD1 ${ }^{-} \mathrm{TIM}^{-}$), partially exhausted $\mathrm{CD}^{+} \mathrm{T}$ cells $\left(\mathrm{PD} 1^{\text {int }} \mathrm{TIM}^{+}\right)$, and completely exhausted $\mathrm{CD}^{+} \mathrm{T}$ cells $\left(\mathrm{PD} 1^{\mathrm{hi}} \mathrm{TIM3}^{+}\right.$) according to the expression of PD1 and TIM3 (Fig. 3A). PD1 TIM3- and PD1 int $\mathrm{TIM}^{+}$cells were selected for in vitro study. Firstly, M2 
A
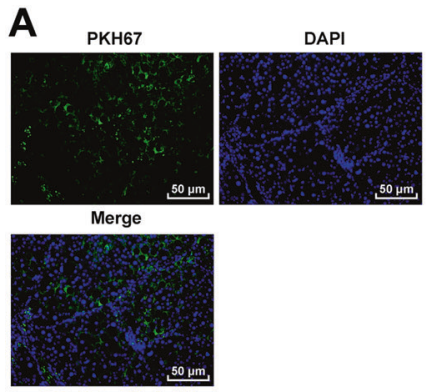

B

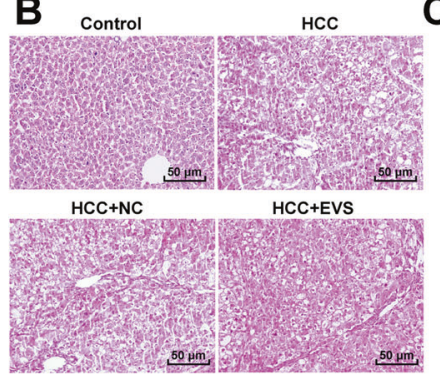

C

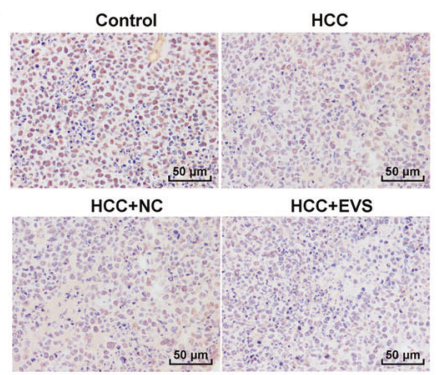

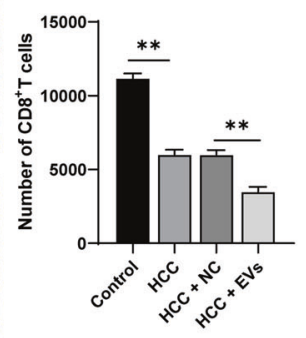

D

PD1
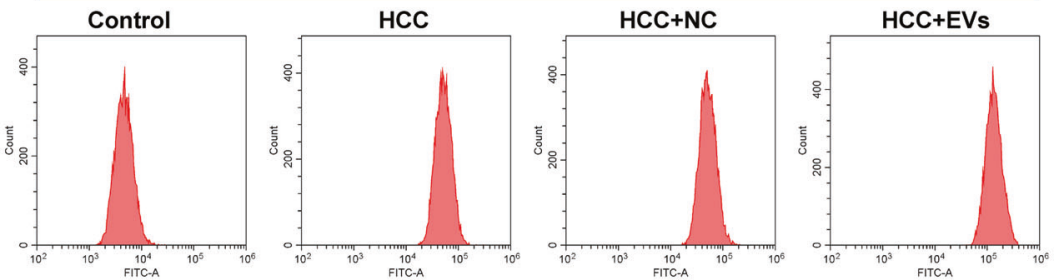

TIM3
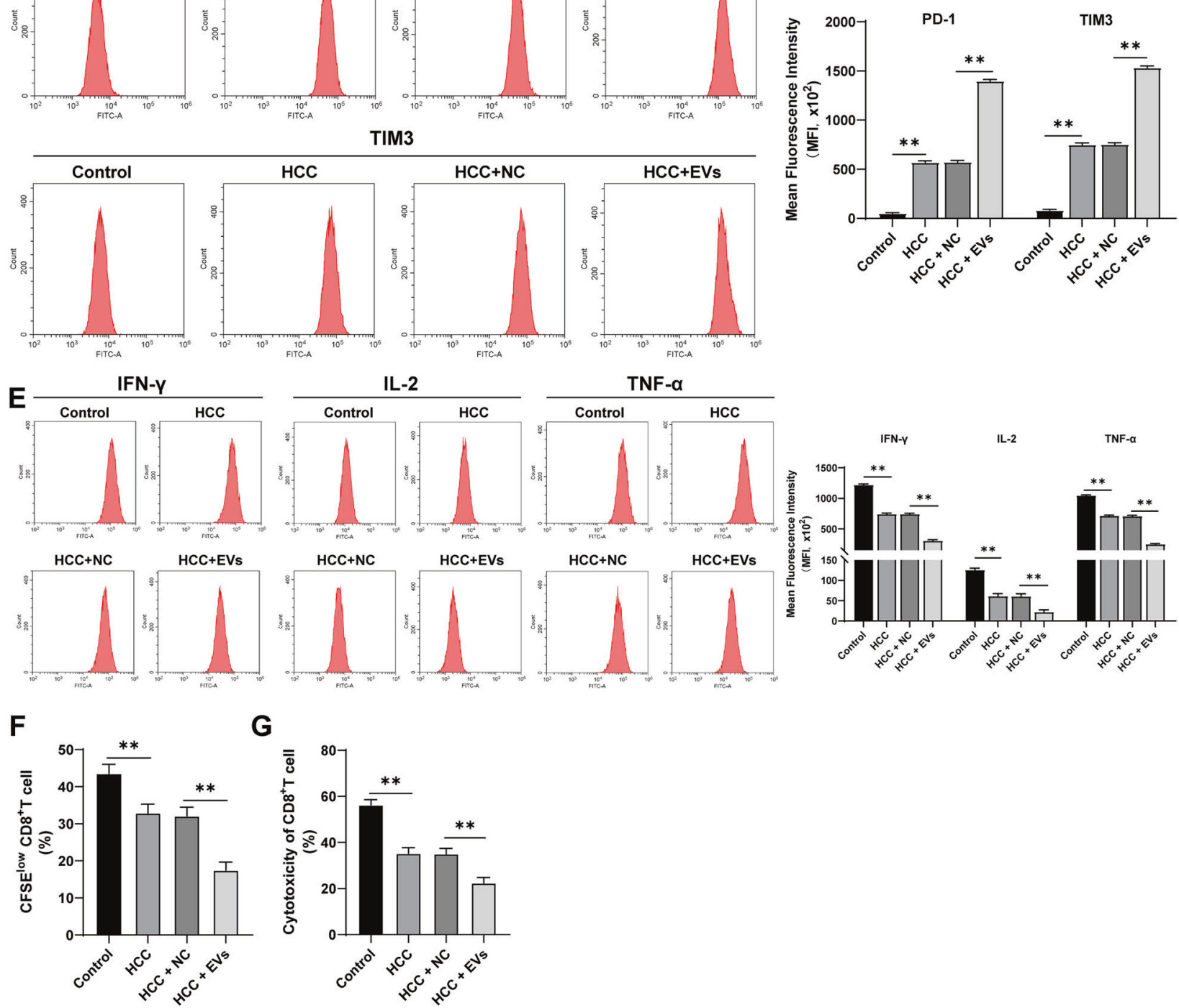

G

Fig. 1 M2 macrophage-derived EVs promoted $\mathrm{CD8}^{+} \mathbf{T}$ cell exhaustion in mice with primary HCC. The murine model of primary HCC was established by DEN/CCl ${ }_{4}$ combined induction, and the model mice were injected with EVs via tail vein. A The absorption of EVs by mouse liver tissues was detected using immunofluorescence. Green indicated PKH67-labeled EVs and blue indicated nuclear staining. B Histopathological changes of liver tissues were observed using HE staining at the $40^{\text {th }}$ week after induction. C The number of CD8 ${ }^{+} \mathrm{T}$ cells in tumor sections was detected using immunohistochemistry. PBMCs were isolated from the mouse liver and CD8 ${ }^{+}$T cells were sorted. D The expressions of immune checkpoint inhibitory receptors (PD1 and TIM3) on $\mathrm{CD}^{+}{ }^{+}$T cells were detected using flow cytometry. E The expressions of effector cytokines (IFN- $\gamma$, IL-2, and TNF- $\alpha$ ) were detected using flow cytometry. $\mathbf{F}$ The proliferation ability of CD8 ${ }^{+} \mathrm{T}_{\text {cells }}$ was measured using flow cytometry. G The ability of $C D 8^{+}$T cells to kill Hep1- 6 cells was measured using flow cytometry. $N=6$. The cell experiment was repeated 3 times. Data are presented as mean \pm standard deviation and analyzed using one-way ANOVA, followed by Tukey's multiple comparison test, ${ }^{* *} p<0.01$. 
A

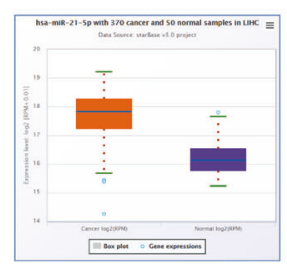

B

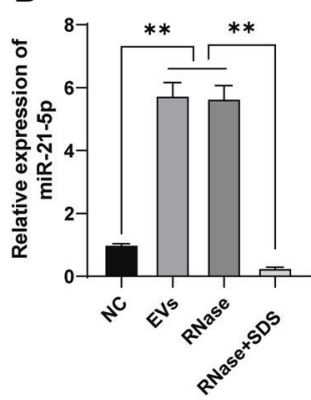

C

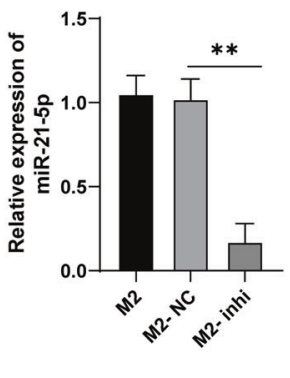

D

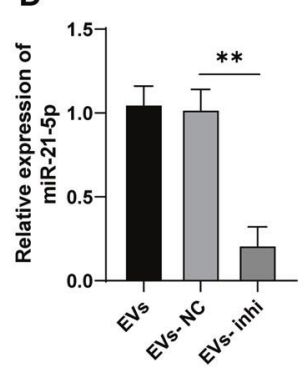

E

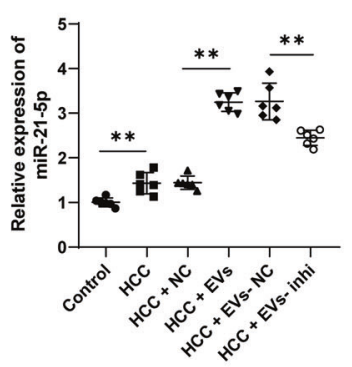

F
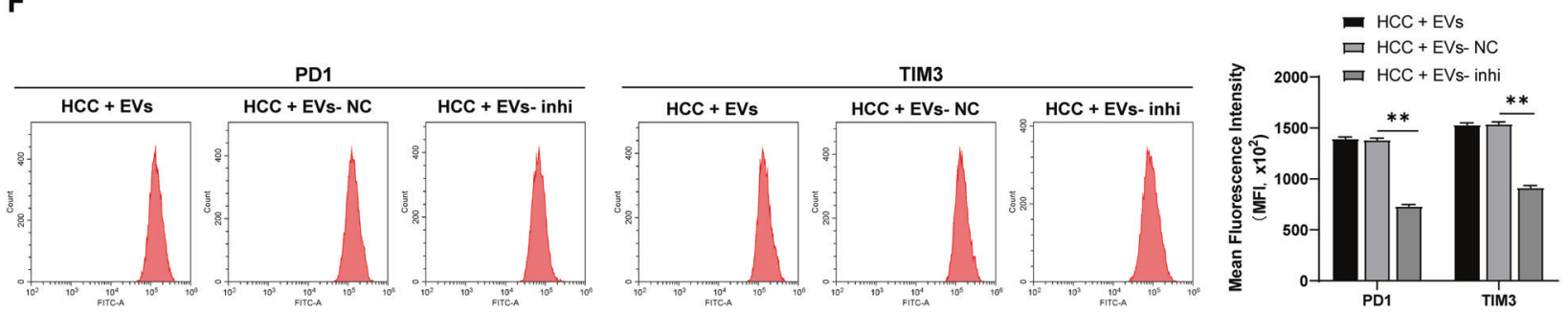

G

IFN-Y
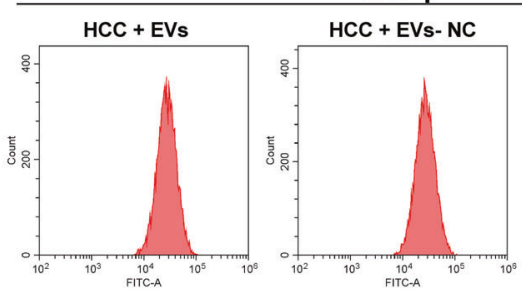

IL-2
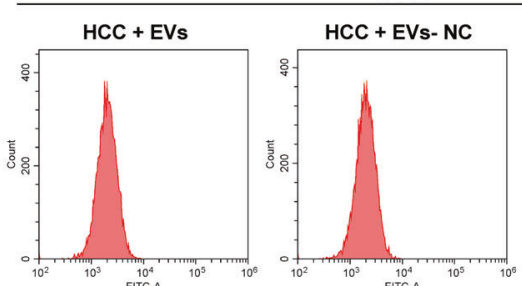

TNF- $\alpha$
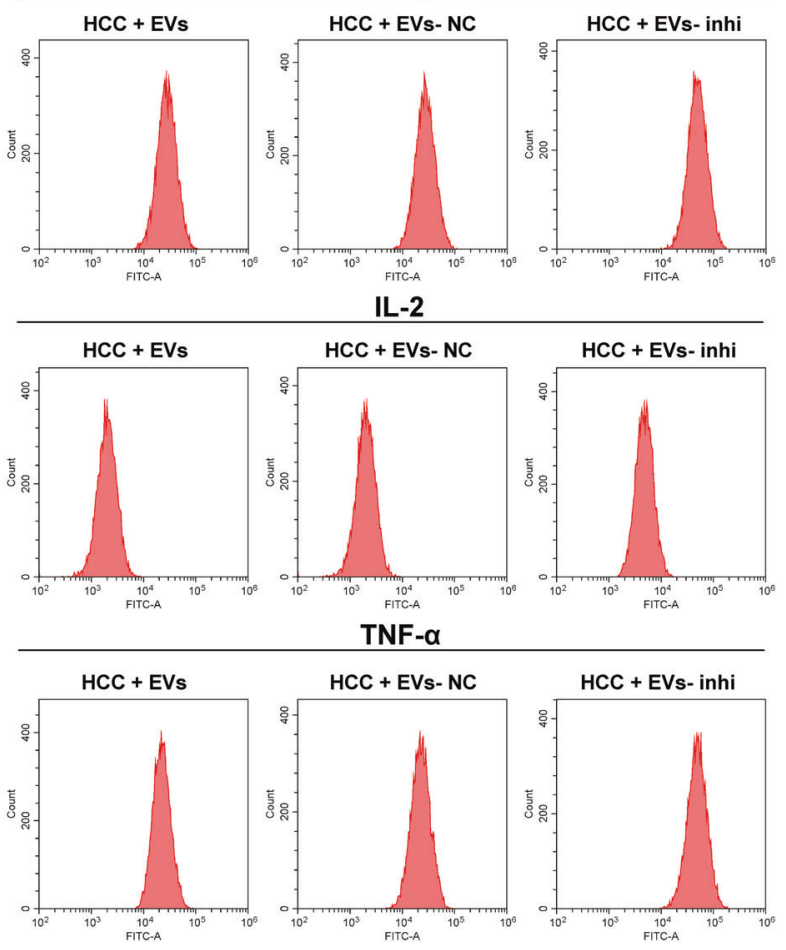

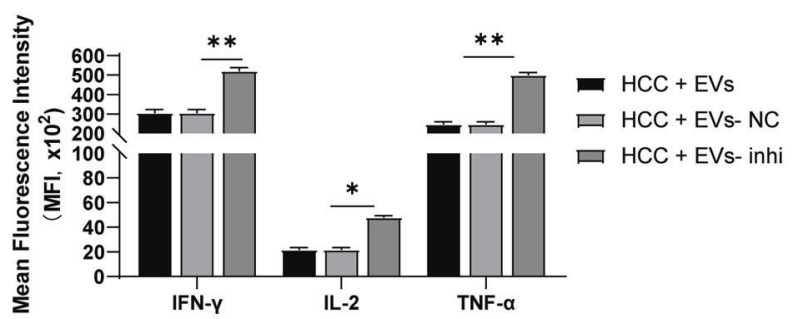

H
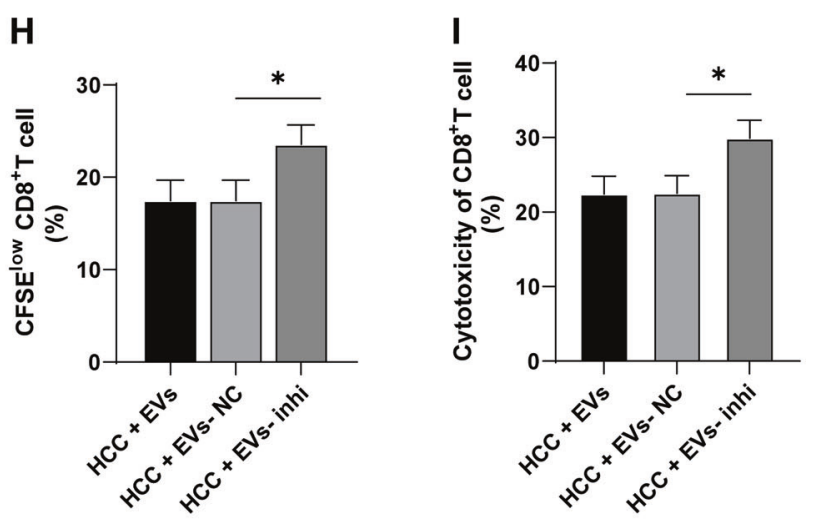

Fig. 2 EVs carried miR-21-5p into the liver tissues of mice. A miR-21-5p expression in HCC was analyzed through the ECORI Pan-Cer database. B miR-21-5p expression in EVs under different treatments was detected using RT-qPCR. M2 macrophages were transfected with miR-21-5p inhibitor. C, D miR-21-5p expression in M2 macrophages and M2 macrophage-derived EVs was detected using RT-qPCR. E HCC mice were injected with EVs under different treatments and the mice were killed after 20 days to obtain liver tissues, and miR-21-5p expression in mouse liver tissues was detected using RT-qPCR. PBMCs were isolated from the mouse liver and CD8 ${ }^{+} \mathrm{T}_{\text {cells }}$ were sorted. $\mathbf{F}$ The expressions of PD1 and TIM3 on CD8 ${ }^{+}$T cell surface were detected using flow cytometry. $\mathbf{G}$ The expressions of effector cytokines (IFN- $\gamma$, IL-2, and TNF- $\alpha$ ) were detected using flow cytometry. $\mathbf{H}$ The proliferation ability of CD8 ${ }^{+} \mathrm{T}$ cells was measured using flow cytometry. I The ability of $\mathrm{CD}^{+}$T cells to kill Hep1-6 cells was measured using flow cytometry. $N=6$. The cell experiment was repeated 3 times. Data are presented as mean \pm standard deviation and analyzed using one-way ANOVA, followed by Tukey's multiple comparison test, ${ }^{*} p<0.05,{ }^{* *} p<0.01$.

macrophage-derived EVs were labeled with PKH67 and cocultured with $\mathrm{CD}^{+} \mathrm{T}$ cells. Under confocal microscopy, EVs were taken up by $\mathrm{CD}^{+} \mathrm{T}$ cells within $3 \mathrm{~h}$ (Fig. 3B). Then the effect of EVs on the function of PD1 $1^{-} \mathrm{TM}^{-}$and PD $1^{\text {int }} \mathrm{TIM}^{+}$ cells were assessed. Consistent with the results in vivo, the EV treatment notably increased the surface expression of cell exhaustion markers on PD1 ${ }^{-} \mathrm{TIM}^{-}$and PD1 $1^{\text {int }} \mathrm{TIM}^{+}$cells, decreased the production of effector cytokines, and weakened proliferation and the ability to kill Hep1-6 cells (all $p<0.01$; Fig. 3C-F). In brief, EVs facilitated $C D 8^{+} \mathrm{T}$ cell exhaustion. 
A

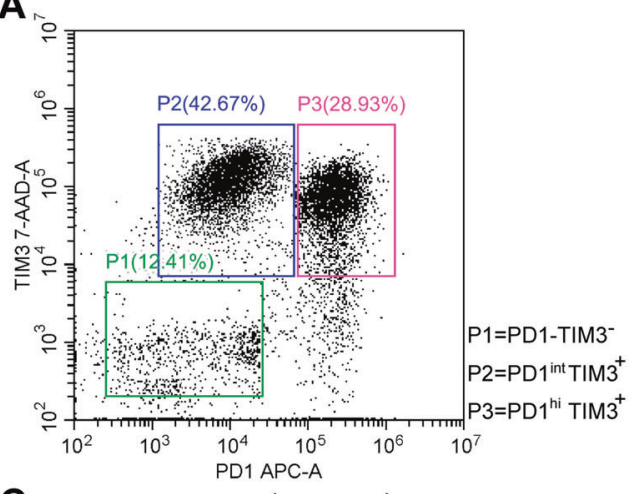

C
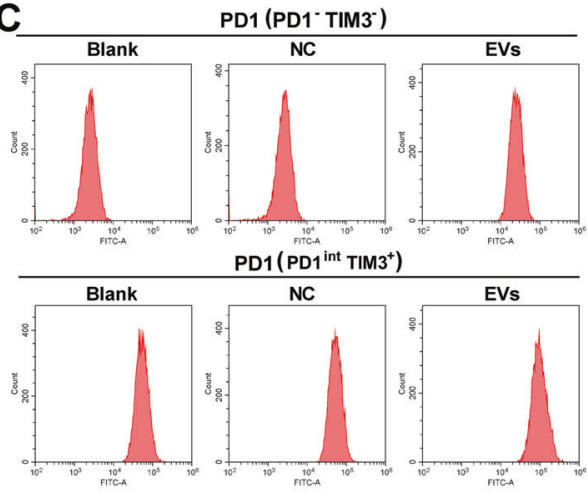

D
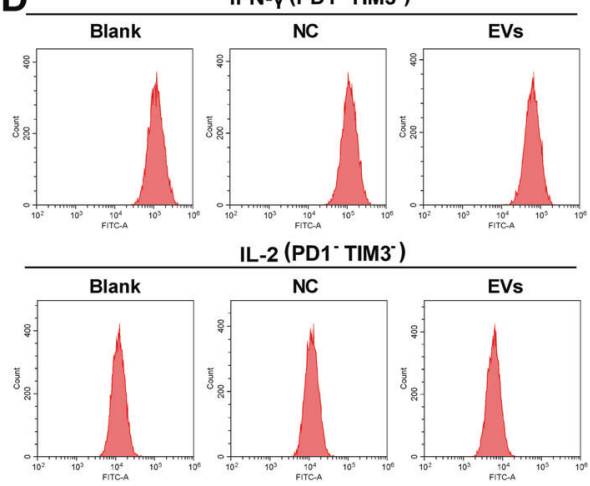

TNF- $\alpha$ (PD1 ${ }^{-}$TIM3$\left.^{-}\right)$
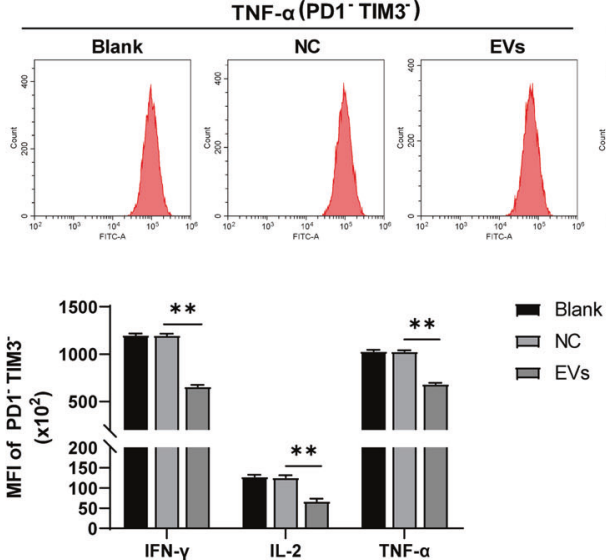

B
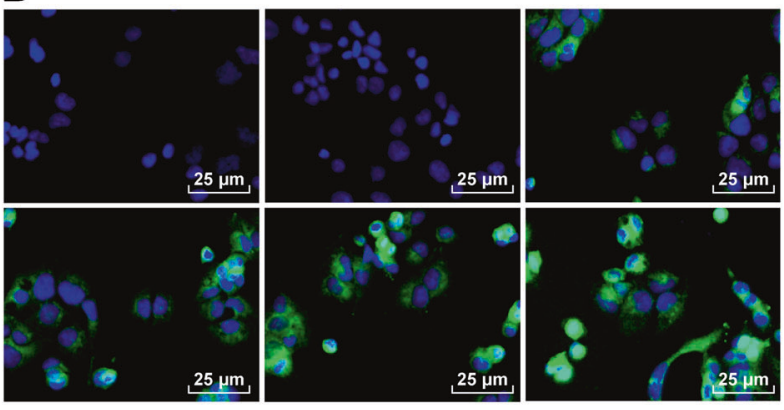

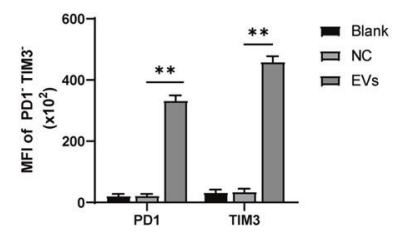

$\operatorname{TIM} 3\left(\mathrm{PD}^{\text {int }} \mathrm{TIM}^{+}\right)$
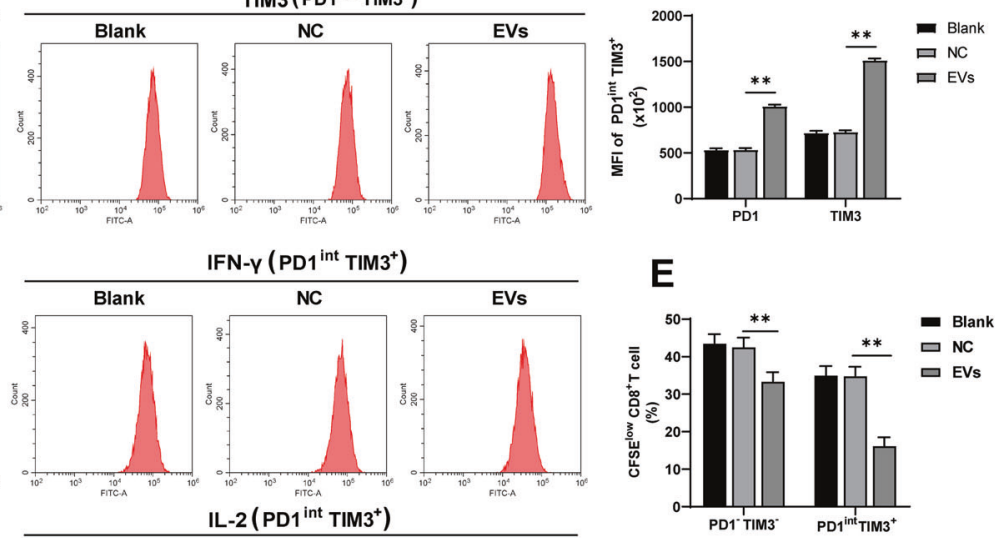

F
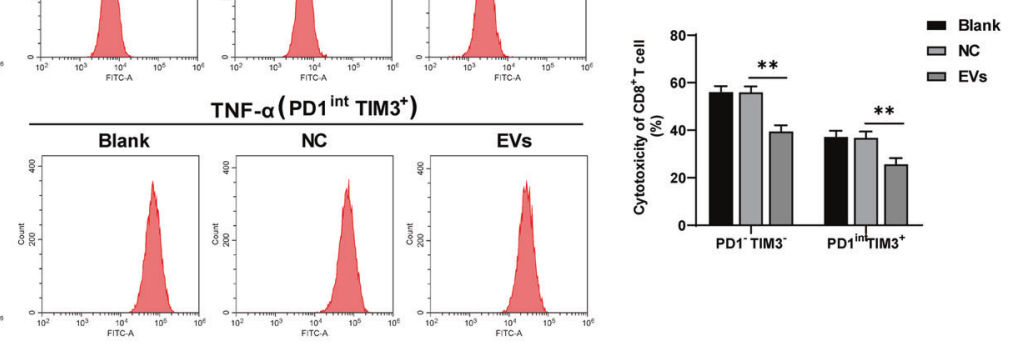

- Blank

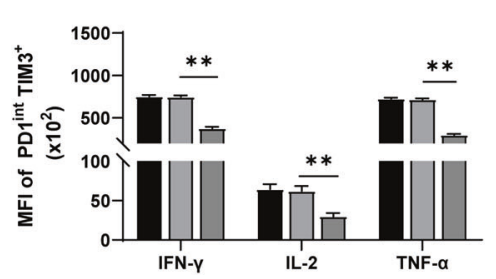

N

घVS

Fig. 3 EVs facilitated CD8 ${ }^{+} \mathbf{T}$ cell exhaustion. A The infiltrating $C D 8^{+} \mathrm{T}$ cells sorted from $\mathrm{HCC}$ mice were divided into three groups: normal

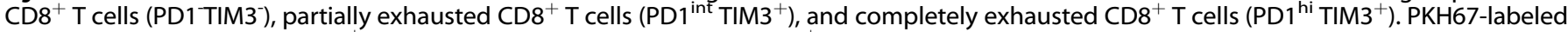
EVs were co-cultured with $\mathrm{CD}^{+} \mathrm{T}$ cells. $\mathbf{B}$ The absorption of EVs by $\mathrm{CD} 8^{+} \mathrm{T}$ cells was detected using immunofluorescence. $\mathrm{C}$ The expressions of inhibitory receptors in CD8 ${ }^{+} \mathrm{T}$ cell surface (PD1 and TIM3) were detected using flow cytometry. D The expressions of effector cytokines (IFN- $\gamma$, IL-2, and TNF- $\alpha$ ) were detected using flow cytometry. $\mathbf{E}$ The proliferation ability of $\mathrm{CD} 8^{+}$cells was measured using flow cytometry. $\mathbf{F}$ The ability of $\mathrm{CD}^{+}$cells to kill Hep1-6 cells was measured using flow cytometry. The cell experiment was repeated 3 times. Data are presented as mean \pm standard deviation and analyzed using one-way ANOVA, followed by Tukey's multiple comparison test, ${ }^{* *} p<0.01$. 
A

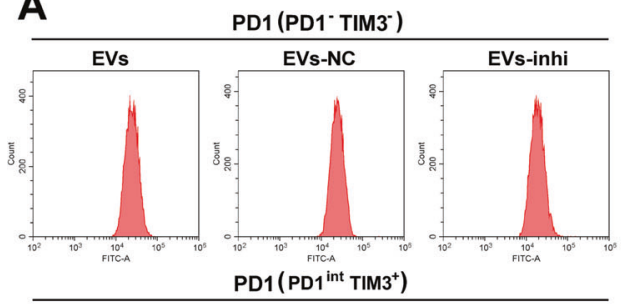

PD1 (PD1 ${ }^{\text {int }}$ TIM3 $^{+}$)

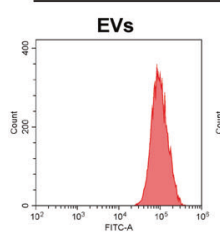

B

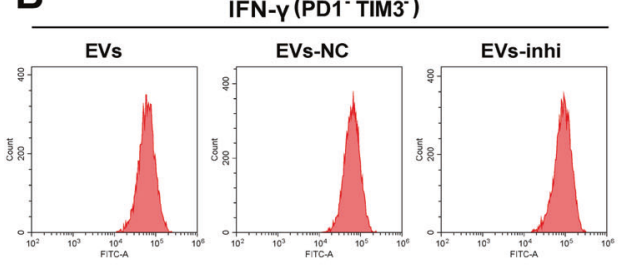

IL-2 (PD1- TIM3*)

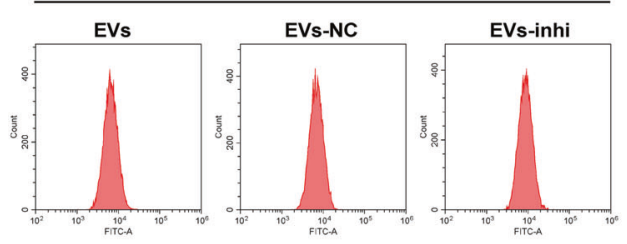

TNF- $\alpha$ (PD1 ${ }^{-}$TIM3 $^{-}$)
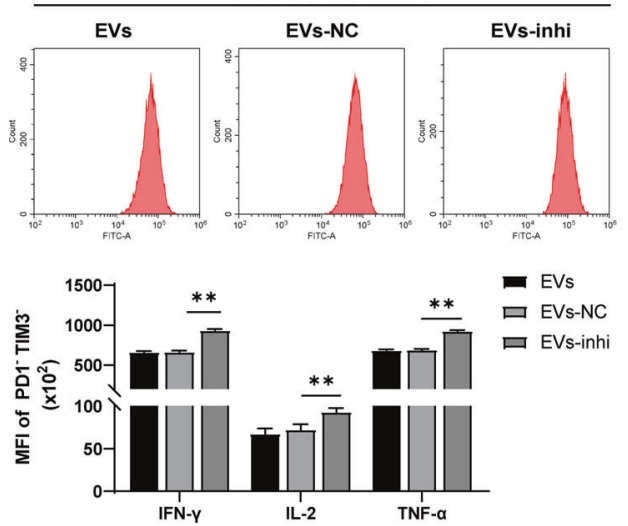

C

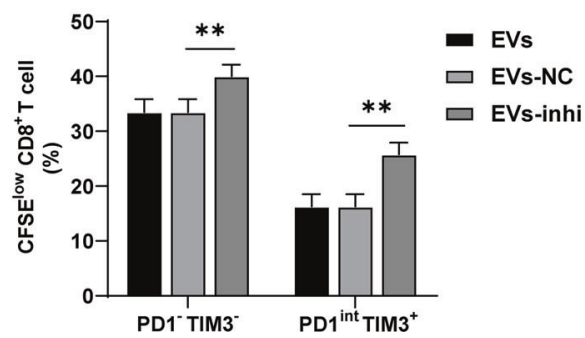

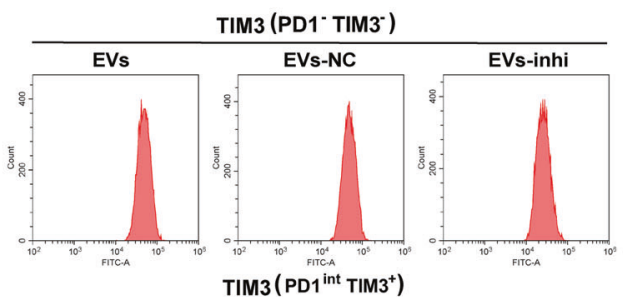

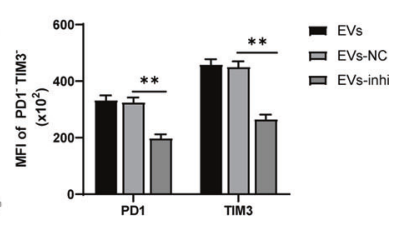

(1)
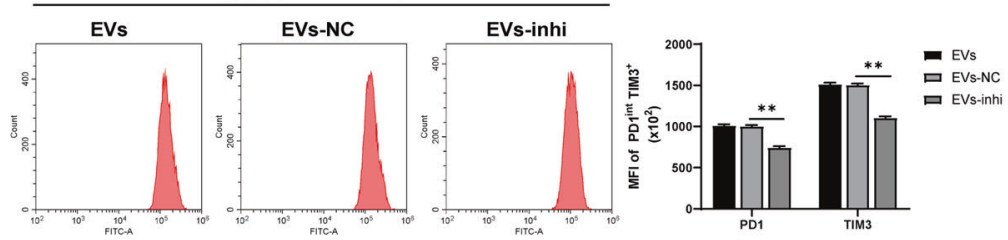

IFN-Y (PD1 ${ }^{\text {int }}$ TIM3 $^{+}$)

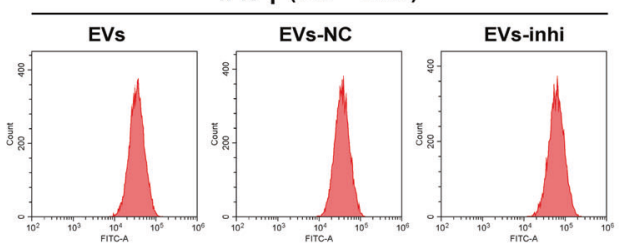

IL-2 (PD1 ${ }^{\text {int }}$ TIM $^{+}$)

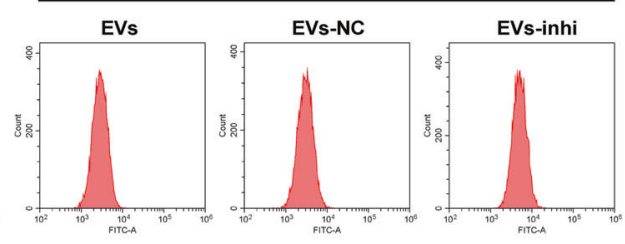

TNF- $\alpha$ (PD1 ${ }^{\text {int }}$ TIM3 $^{+}$)
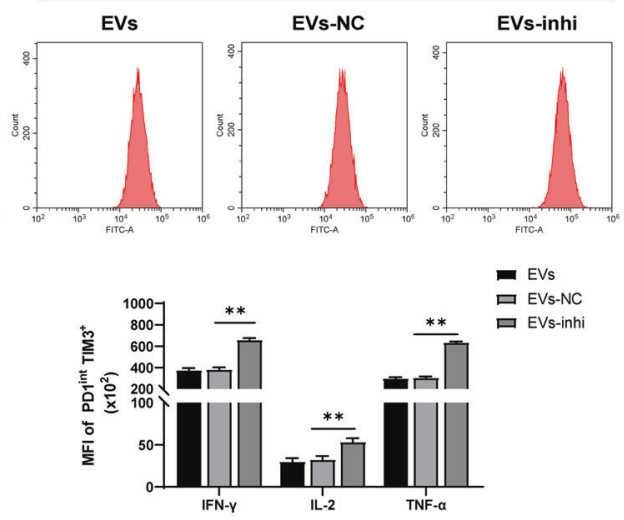

D

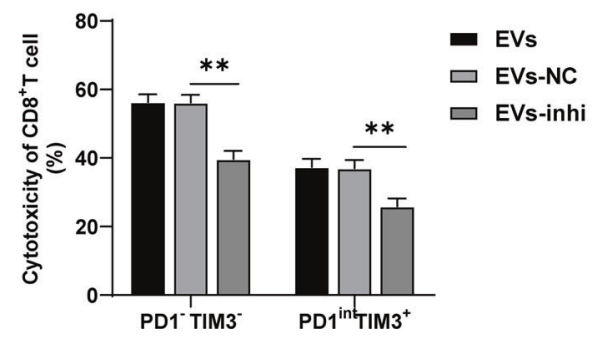

Fig. 4 Inhibition of miR-21-5p in EVs partially reversed the promoting effect of EVs on CD8 ${ }^{+} \mathbf{T}$ cell exhaustion. M2 macrophages were transfected with miR-21-5p inhibitor and then EVs were isolated. The isolated EVs were co-cultured with PD1 TIM3 ${ }^{-}$and PD1 ${ }^{\text {int }}$ TIM3 $^{+}$cells. A The expressions of PD1 and TIM3 were detected using flow cytometry. B The expressions of IFN- $\gamma$, IL-2, and TNF- $\alpha$ were detected using flow cytometry. C The proliferation ability of $\mathrm{CD} 8^{+}$cells was measured using flow cytometry. D The ability of CD8 ${ }^{+}$cells to kill Hep1-6 cells was measured using flow cytometry. The cell experiment was repeated 3 times. Data are presented as mean \pm standard deviation and analyzed using one-way ANOVA, followed by Tukey's multiple comparison test, ${ }^{* *} p<0.01$. 
A starBase

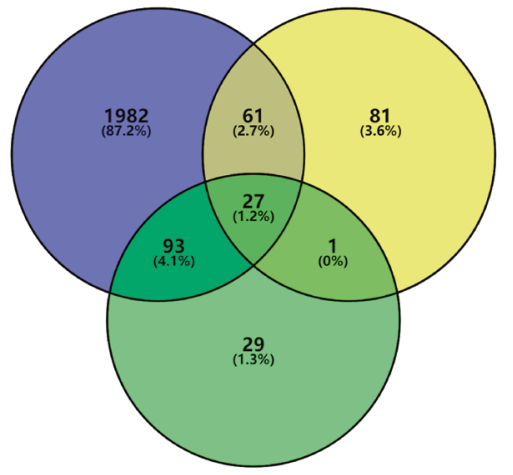

D

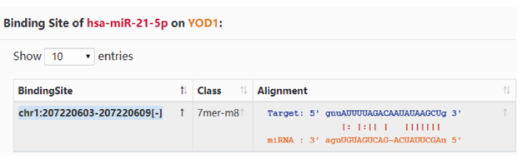

B

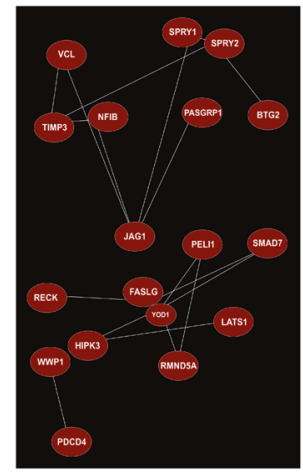

C

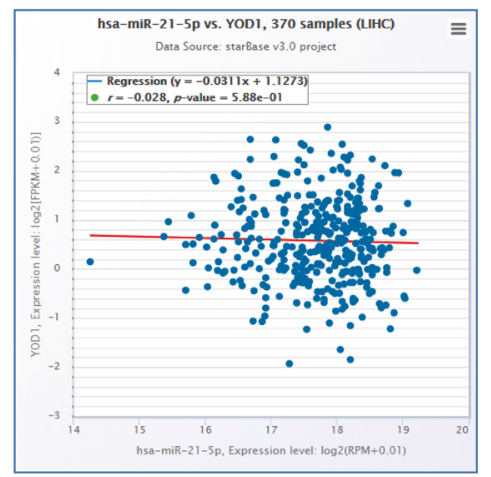

E

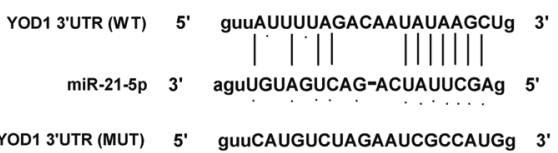

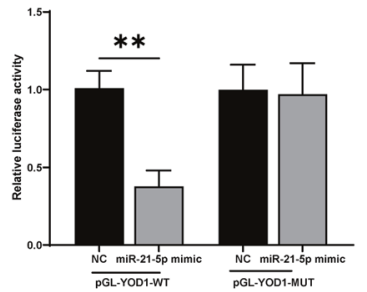

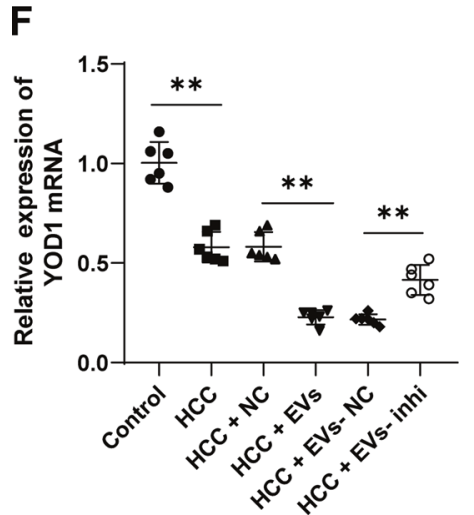

G

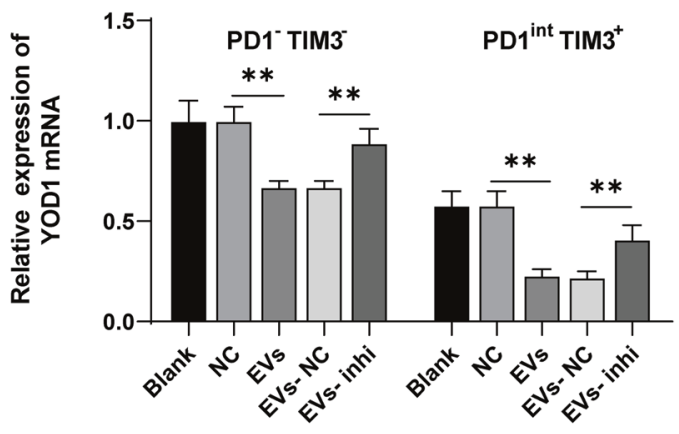

Fig. 5 miR-21-5p targeted YOD1. A Venn diagram of downstream genes of miR-21-5p predicted through Starbase, RNAlnter, and miRDB databases. B Coexpression network of candidate genes was analyzed through the Coexpedia database. C The correlation between the expressions of miR-21-5p and YOD1 was analyzed through the ECORI Pan-Cer database. D The targeting relationship between miR-21-5p and YOD1 was predicted through the StarBase database. E The targeting relationship between miR-21-5p and YOD1 was verified using a dualluciferase assay. F, G YOD1 mRNA expression in mouse liver $(\mathbf{F})$ and $C D 8^{+}$T cells $(\mathbf{G})$ was detected using RT-qPCR. $N=6$. The cell experiment was repeated 3 times. Data are presented as mean \pm standard deviation and analyzed using one-way ANOVA, followed by Tukey's multiple comparison test, ${ }^{* *} p<0.01$.

\section{Inhibition of miR-21-5p in EVs partially reversed the promoting effect of EVs on $\mathrm{CDB}^{+} \mathrm{T}$ cell exhaustion}

To further determine whether M2 macrophage-derived EVs promote $\mathrm{CD}^{+}{ }^{+} \mathrm{T}$ cell exhaustion through miR-21-5p, EVs under different treatments were co-cultured with PD1 ${ }^{-} \mathrm{TIM}^{-}$and $\mathrm{PD}^{\text {int }} \mathrm{TIM3}^{+}$cells, and then the exhaustion of PD1 ${ }^{-} \mathrm{TIM}^{-}$and $\mathrm{PD}^{\text {int }} \mathrm{TIM3}^{+}$cells was measured. The results elicited that inhibition of miR-21-5p in EVs partially reversed the promoting effect of EVs on PD1 ${ }^{-} \mathrm{TIM}^{-}$and PD $1^{\text {int }} \mathrm{TIM}^{+}$cell exhaustion (all $p<0.01$; Fig. 4A-D)

\section{miR-21-5p targeted YOD1}

To further explore the regulatory mechanism of miR-21-5p promoting $\mathrm{CD}^{+} \mathrm{T}$ cell exhaustion in EVs, the downstream targets of miR-21-5p were predicted through Starbase, RNAlnter, and miRDB databases (Fig. 5A). The Coexpedia database was used to explore the coexpression network of genes to further screen target genes. According to the coexpression relationship score of the website, SPRY2 and YOD1 showed higher scores (score = $9.825,9.200$ ) (Fig. 5B). The antigen cross-presentation is regulated by the activity of deubiquitinase YOD1, which may help to control the immune response of antigen-specific $\mathrm{CD}^{+} \mathrm{T}$ cells in the immune process [25]. Additionally, the ECORI Pan-Cer database showed that miR-21-5p and YOD1 were negatively correlated in HCC (Fig. 5C), and there was a binding site between miR-21-5p and YOD1 3'UTR sequence (Fig. 5D). The binding relationship between miR-21-5p and YOD1 was further verified using dualluciferase assay ( $p<0.01$; Fig. $5 \mathrm{E})$. Furthermore, YOD1 expression in the liver and $C D 8^{+}$T cells was detected. The results revealed that YOD1 mRNA expression in mouse liver and PD1 ${ }^{-} \mathrm{TIM}^{-}$and $\mathrm{PD}^{1}{ }^{\text {int }} \mathrm{TIM}^{+}$cells was notably decreased after EV treatment, and YOD1 mRNA expression was increased after inhibition of miR-21$5 p$ in EVs (all $p<0.01$; Fig. 5F, G). Taken together, there was a negative regulatory relationship between miR-21-5p and YOD1.

\section{Overexpression of YOD1 averted the effect of EVs on CD8 ${ }^{+}$ $T$ cell exhaustion}

To explore the role of YOD1 in EVs promoting $\mathrm{CD}^{+} \mathrm{T}$ cell exhaustion, PD1 $\mathrm{TIM}^{-}$and $\mathrm{PD} 1^{\text {int }} \mathrm{TIM3}^{+}$cells were transfected with pcDNA-YOD1 and then treated with EVs. RT-qPCR showed 
that YOD1 mRNA expression in PD1 ${ }^{-} \mathrm{TIM}^{-}$and $\mathrm{PD} 1^{\text {int }} \mathrm{TIM}^{+}$cells were increased after oe-YOD1 transfection (all $p<0.05$; Fig. 6A). Overexpression of YOD1 reversed the promoting effect of EVs on $\mathrm{CD}^{+} \mathrm{T}$ cell exhaustion (all $p<0.05$; Fig. 6B-E).

\section{YOD1 inhibited the YAP/ $\beta$-catenin pathway}

YOD1 and YAP expressions are closely related to HCC, and YOD1 is a regulator of the Hippo pathway and a potential target for the treatment of HCC [26]. YAP in the Hippo pathway attenuates CD8 ${ }^{+}$ $\mathrm{T}$ cell-mediated tumor responses [27]. Activation of $\beta$-catenin promotes immune escape in HCC cells [28]. Western blotting showed that compared with control mice, HCC mice had elevated expressions of YAP and $\beta$-catenin, and EV treatment further enhanced their expressions (all $p<0.01$; Fig. 7A). To further investigate the effect of YOD1 on the YAP/ $\beta$-catenin pathway, we overexpressed YOD1 in EV-treated PD1 TIM3 $3^{-}$and PD1 $1^{\text {int }} \mathrm{TIM}^{+}$ cells. The results revealed that the expressions of YAP and $\beta$-catenin were clearly decreased after YOD1 overexpression (both $p<0.01$; Fig. 7B). Briefly, YOD1 inhibited the YAP/ $\beta$-catenin pathway.

\section{DISCUSSION}

HCC is an aggressive malignant tumor associated with unfavorable outcomes, and immune checkpoint-based therapy has been recognized to be a promising strategy for HCC management [8]. The crosstalk between HCC cells and TME components drives the immune evasion of HCC, and tumor-associated M2 macrophages are the primary components of TME [29], which facilitate the progression and invasiveness of HCC [30]. This study elucidated that $\mathrm{M} 2$ macrophage-derived EVs promoted $\mathrm{CD} 8^{+}$cell exhaustion in HCC via the miR-21-5p/YOD1/YAP/ $\beta$-catenin pathway (Fig. 8).

Immune cells in TME interact with tumor cells directly or via chemokine and cytokine signalings, thus affecting tumor cell behaviors and therapeutic response [16]. M2 macrophages can enhance tumor angiogenesis, matrix remodeling, and adaptive immunity suppression [17], which are concerned with poorer outcomes and worse pathological characteristics of HCC patients [31]. After the murine model of primary HCC was established by DEN/ $\mathrm{CCl}_{4}$ combined induction in the present study, EVs were injected into liver tissues of model mice. The results demonstrated that EV treatment promoted the tumorigenesis of mice, with a higher malignant degree of the tumor. During chronic infection and cancer progression, $\mathrm{T}$ cells are exposed to persistent antigen and/or inflammatory signals, leading to an exhausted status [11]. The exhausted $\mathrm{CD}^{+} \mathrm{T}$ cell constitutes a major obstacle to effective immunotherapy in HCC [10]. In this study, the number of infiltrating $\mathrm{CD}^{+} \mathrm{T}$ cells in HCC mice was significantly reduced, and EV treatment further reduced the number of infiltrating $\mathrm{CD}^{+} \mathrm{T}$ cells in HCC tissues.

The exhausted $\mathrm{CD} 8^{+} \mathrm{T}$ cells are characterized by the gradual loss of effector functions including cytokine production, killing function, the generation of inhibitory receptors, metabolic disorder, and homeostatic proliferation [32]. Then, we isolated PBMCs from the mouse liver and sorted $\mathrm{CD}^{+} \mathrm{T}$ cells. PD1 and TIM3 are commonly overexpressed in exhausted $\mathrm{CD}^{+} \mathrm{T}$ cells, and the intensity of inhibitory receptors is positively correlated with the degree of $\mathrm{CD}^{+} \mathrm{T}$ cell exhaustion [11]. In the current study, HCC mice showed notably enhanced expressions of immune checkpoint inhibitory receptors PD1 and TIM3 and reduced expressions of effector cytokines IFN- $\gamma$, IL-2, and TNF-a, indicating that $\mathrm{CD}^{+} \mathrm{T}$ cells in HCC mice were in a functional exhaustion state. The addition of EVs further increased the expressions of $\mathrm{CD}^{+}$cell exhaustion surface markers, decreased the production of effector cytokines, and weakened the proliferation ability of $\mathrm{CD}^{+}$cells and the ability to kill Hep1-6 cells. EVs derived from cord blood stem cells are more likely to interact with monocytes in PBMCs and induce the differentiation of purified monocytes into M2 macrophages, which can downregulate the percentage of activated $\mathrm{CD}^{+} \mathrm{T}$ cells [33].
Briefly, M2 macrophage-derived EVs promoted $\mathrm{CD}^{+}$cell exhaustion in mice with primary HCC.

It is well established that EVs can facilitate tumor progression and metastasis via the delivery of multiple molecules, including miRNAs [34]. Aberrant miRNA expression has been commonly accepted as a promising biomarker for the diagnosis and treatment of HCC [35]. miR-21 represents one of the earliest discovered oncogenes, which can target a variety of tumor suppressor genes related to proliferation, apoptosis, and invasion [36]. Emerging evidence has revealed that the elevated miR-21 expression facilitates HCC progression [37, 38]. Hence, miR-21-5p expression in $M 2$ macrophage-derived EVs was detected, and the results revealed that miR-21-5p expression in EVs was notably increased. We speculated that M2 macrophage-derived EVs promoted $\mathrm{CD}^{+} \mathrm{T}$ cell exhaustion in HCC through miR-21-5p. M2 macrophages were transfected with miR-21-5p inhibitor and then EVs were extracted (EVs-inhi). EVs-inhi treatment partially reversed the promoting effect of EVs on $\mathrm{CD}^{+} \mathrm{T}$ cell exhaustion in mice with primary HCC. Notably, leukemia cell-derived EVs have been demonstrated to trigger $T$ cell exhaustion via miR-21-5p delivery [24]. These results suggested that EVs facilitated $\mathrm{CD}^{+} \mathrm{T}$ cell exhaustion in mice with primary $\mathrm{HCC}$ by carrying miR-21-5p. Knockdown of miR-21 can enhance $\mathrm{CD} 8^{+} \mathrm{T}$ cell proliferation and cell cytotoxic activity in glioma [39]. miR-21 antagomir upregulated the proportion of $\mathrm{CD}^{+}$and $\mathrm{CD}^{+} \mathrm{T}$ cells in lung cancer tissues, implying that inhibition of miR-21 retards the immunosuppressive ability of myeloid-derived suppressor cells on lung cancer [40]. For the in vitro study, PD1 $\mathrm{TIM}^{-}$and PD1 ${ }^{\text {int }} \mathrm{TIM}^{+}$ cells were cultured with EVs to further determine the effect of EVs on $\mathrm{CD}^{+} \mathrm{T}$ cell exhaustion. The results were consistent with those of the in vivo experiments and confirmed that EVs facilitated $\mathrm{CD} 8^{+} \mathrm{T}$ cell exhaustion by carrying miR-21-5p.

Subsequently, we screened the target genes of miR-21-5p through the databases. YOD1 is a member of deubiquitinating enzymes of Otubain domain [41]. Although it is suggested that YOD1 can act as a potential therapeutic target for liver cancer [42], the exact role of YOD1 in HCC remains controversial yet. This study verified the negative regulatory relationship between miR-21-5p and YOD1. Overexpression of YOD1 reversed the effect of EVs on $\mathrm{CD}^{+}$cell exhaustion. YOD1 provides exogenous antigens to $\mathrm{CD} 8^{+}$ cells and thus controls antigen-specific $\mathrm{CD}^{+}$cell response during immunization [25]. Then we determined the downstream pathway regulated by the miR-21-5p/YOD1 axis in HCC. A close correlation between YOD1 and YAP expression can be observed in patients with liver cancer [42]. YAP serves as a sensor of the structural and mechanical characteristics in the cell microenvironment [43]. The strict control of YAP activity is essential for the homeostasis of normal tissues and activated YAP results in excessive tissue growth, stem cell expansion, and tumorigenesis [44]. YAP is deregulated in $\mathrm{HCC}$ and emerged as a promising target for HCC therapies [44]. Aberrant activation of the $\beta$-catenin pathway is frequently observed in HCC patients, which is implicated in drug resistance, tumor initiation, progression, and metastasis [45]. In this study, HCC mice showed elevated expressions of YAP and $\beta$-catenin, and EV treatment further enhanced their expressions. Furthermore, we overexpressed YOD1 in PD1 TIM3 ${ }^{-}$and PD1 $1^{\text {int }} \mathrm{TIM}^{+}$cells treated with EVs. The results revealed that the expressions of YAP and $\beta$-catenin were decreased after YOD1 overexpression. YAP plays an immunosuppressive role in $\mathrm{CD}^{+}$cells, especially in activated cytotoxic cells in the TME [27]. Additionally, $\beta$-catenin signaling regulates $T$ cell inflammation and restores $T$ cell infiltration in the TME [46]. Inhibition of YAP can restore hepatocyte differentiation in advanced HCC, thereby contributing to tumor regression [47]. Collectively, YOD1 inhibited the YAP/ $\beta$-catenin pathway.

To conclude, miR-21-5p carried by M2 macrophage-derived EVs could promote $\mathrm{CD}^{+} \mathrm{T}$ cell exhaustion in HCC via targeting YOD1 and activating the YAP/ $\beta$-catenin pathway. However, this study failed to investigate the role of EVs in HCC at the clinical level. Additionally, the existing study has unveiled that YAP not only 


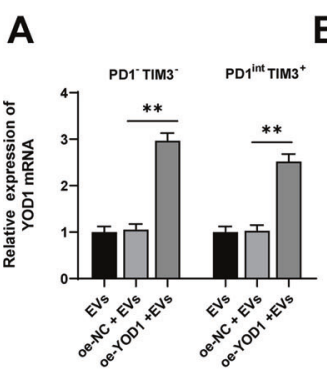

B
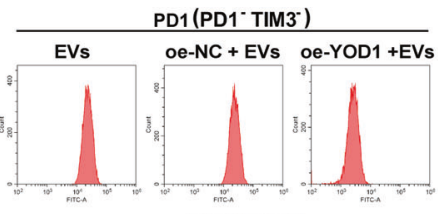

PD1 (PD1 ${ }^{\text {int }} \mathrm{TIM3}^{+}$)

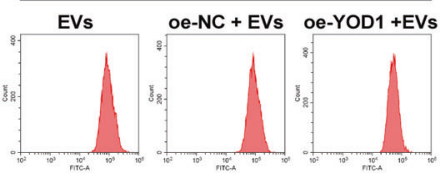

C

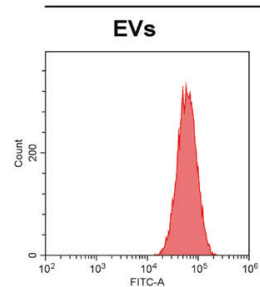

IFN-Y (PD1- ${ }^{-}$TIM3-) $^{-}$

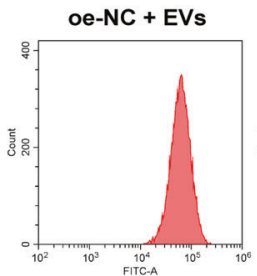

IL-2 (PD1 ${ }^{-}$TIM3 $^{-}$)
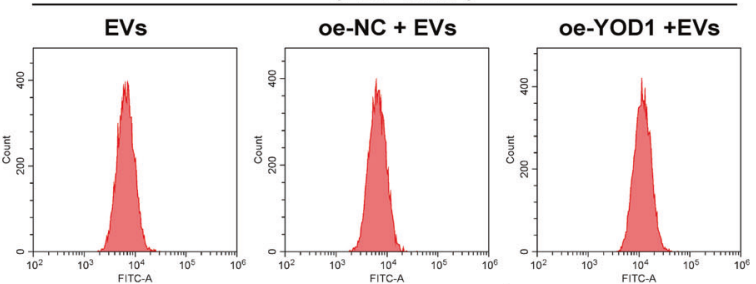

TNF- $\alpha$ (PD1 ${ }^{-}$TIM3 $\left.^{-}\right)$
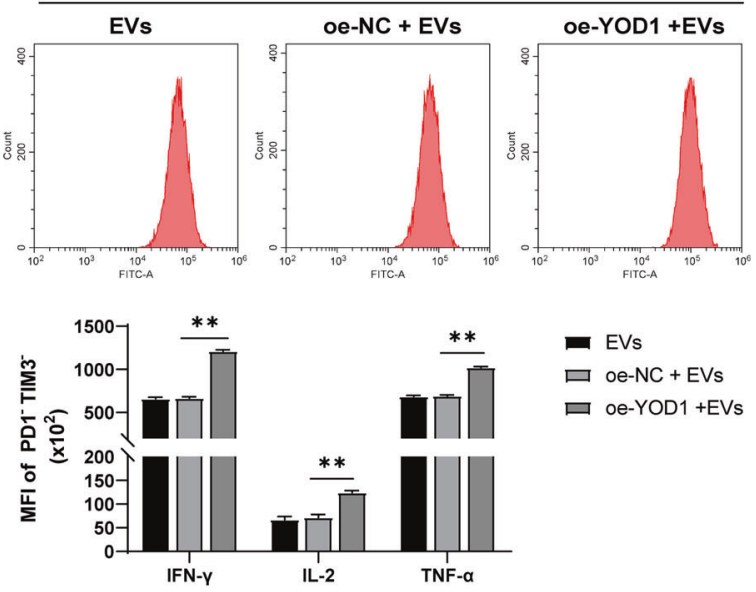

- EVs

口 oe-NC + EVs

口 oe-YOD1+EVs
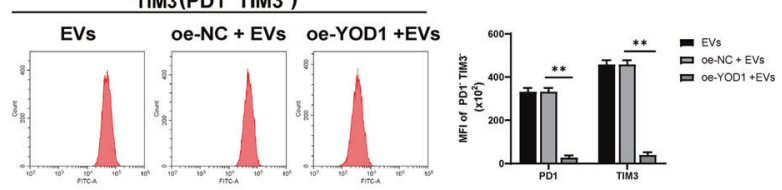

TIM3 (PD1 ${ }^{\text {int }}$ TIM3 $^{+}$)

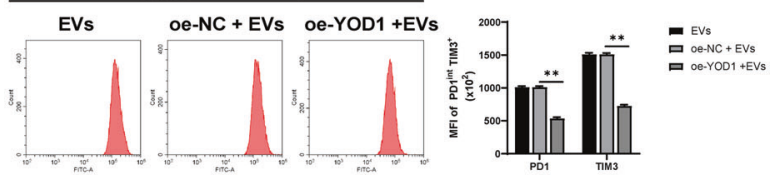

IFN-Y (PD1 ${ }^{\text {int }}$ TIM3 $\left.^{+}\right)$

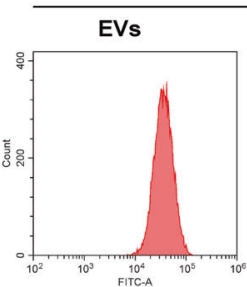

oe-NC + EVs

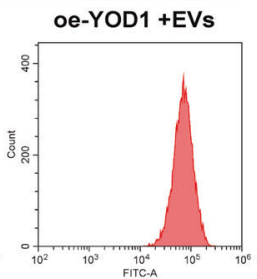

IL-2 (PD1 ${ }^{\text {int }}$ TIM $^{+}$)
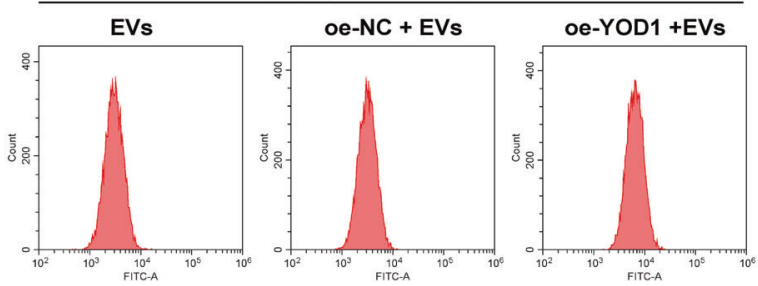

TNF- $\alpha$ (PD1 ${ }^{\text {int }} \mathrm{TIM3}^{+}$)
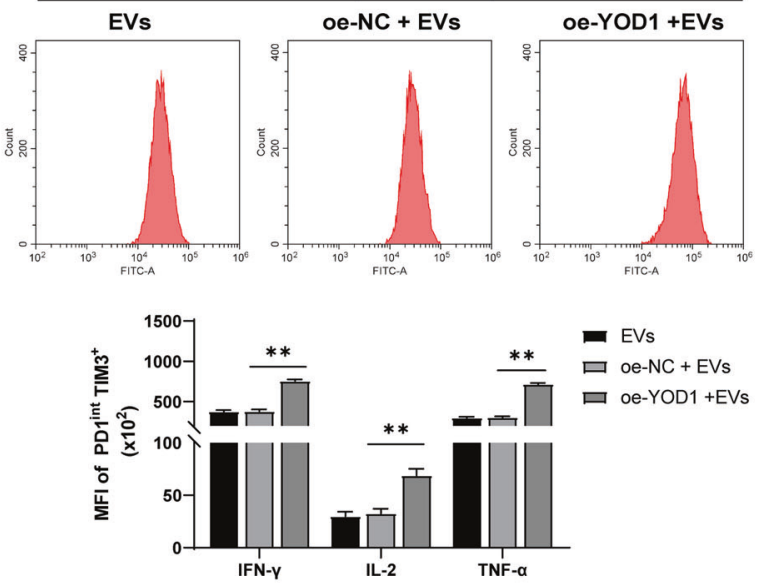

D

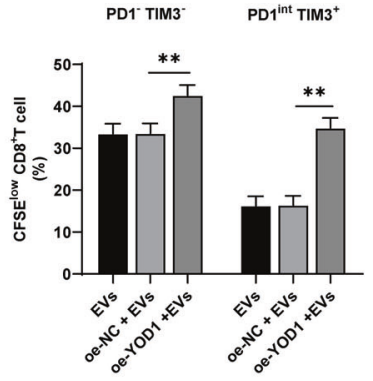

E

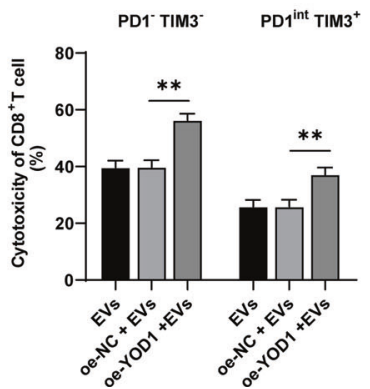

Fig. 6 Overexpression of YOD1 reversed the effect of EVs on CD8 ${ }^{+} \mathrm{T}$ cell exhaustion. pcDNA-YOD1-transfected CD8 ${ }^{+} \mathrm{T}_{\text {cells }}$ were treated with EVs. A YOD1 mRNA expression was detected using RT-qPCR. B The expressions of PD1 and TIM3 were detected using flow cytometry. C The expressions of IFN- $\gamma$, IL-2, and TNF- $\alpha$ were detected using flow cytometry. D The proliferation ability of PD $1{ }^{-T_{I M M}}{ }^{-}$and PD ${ }^{\text {int }}$ TIM $^{+}{ }^{+}$cells was measured using flow cytometry. E The ability of PD1 ${ }^{-} \mathrm{TIM}^{-}$and PD1 ${ }^{\text {int }}{ }^{-\mathrm{TIM}^{+}}{ }^{+}$cells to kill Hep1-6 cells was measured using flow cytometry. The cell experiment was repeated 3 times. Data are presented as mean \pm standard deviation and analyzed using one-way ANOVA, followed by Tukey's multiple comparison test, ${ }^{* *} p<0.01$. 

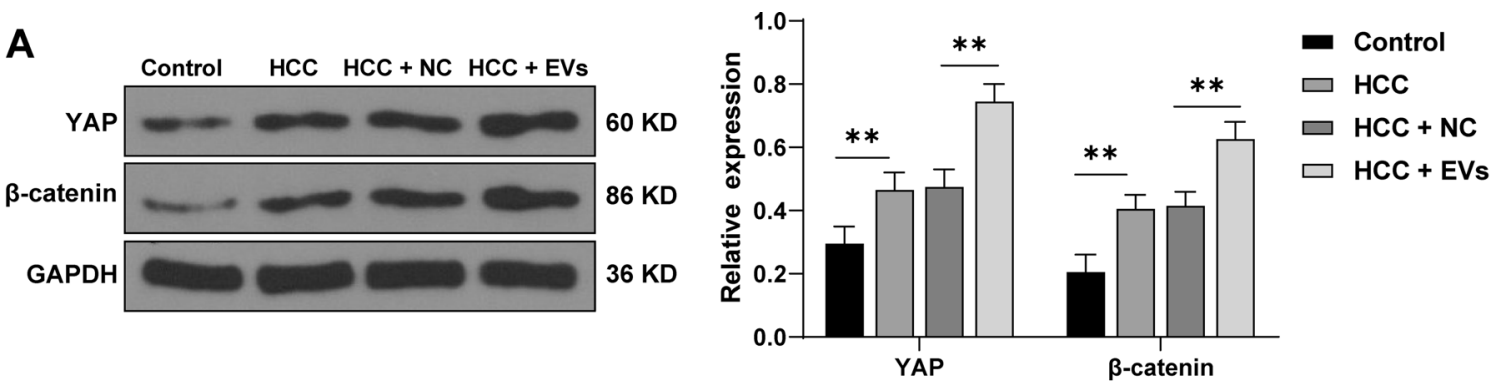

PD1 $^{-}$TIM3 $^{-}$
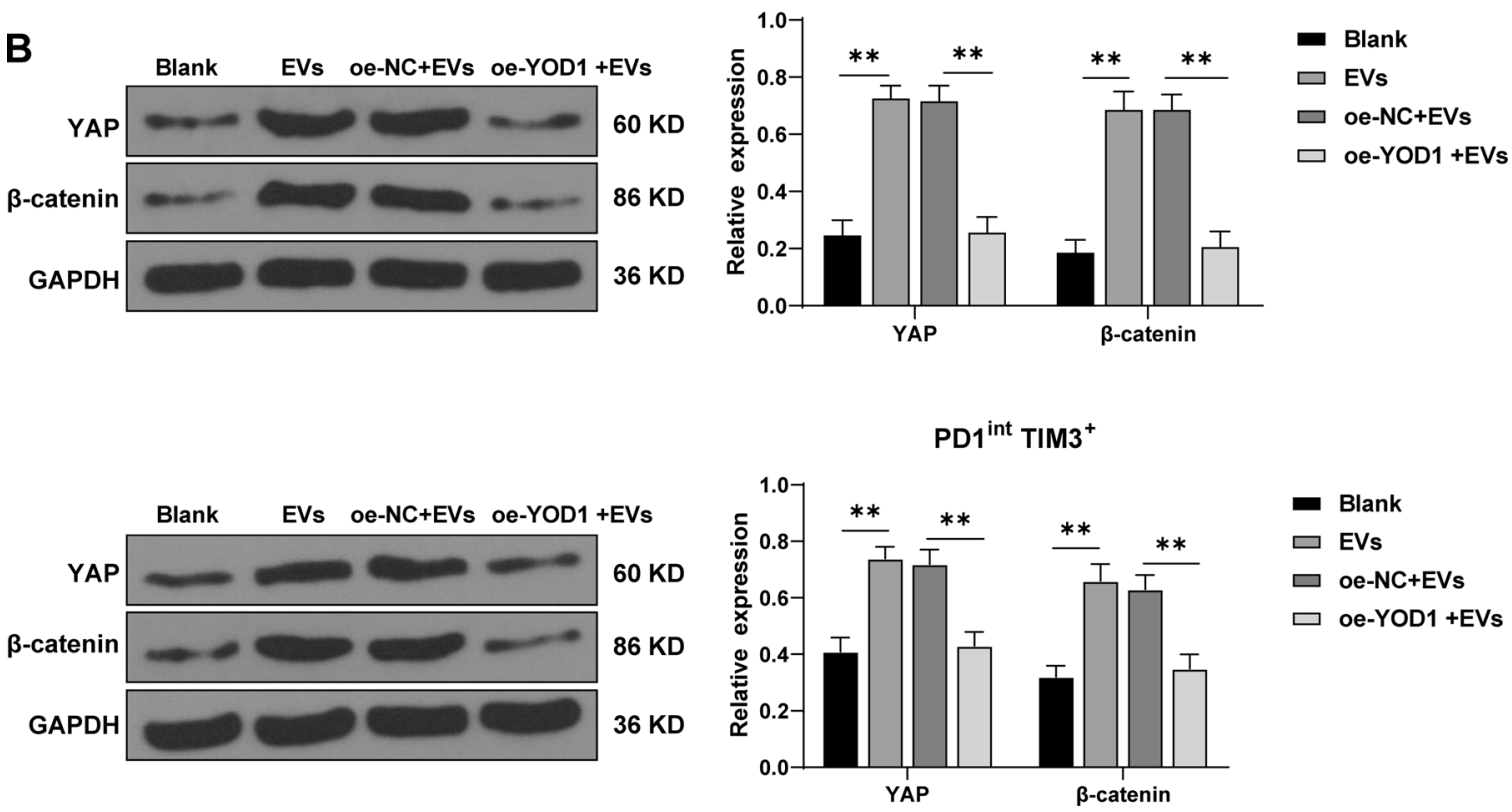

Fig. 7 YOD1 inhibited the YAP/ $\beta$-catenin pathway. A, B The levels of YAP and $\beta$-catenin in HCC mouse liver and PD1 TIM3 $^{-}$and PD $1^{\text {int }}$ TIM $^{+}$ cells were detected using Western blotting. $N=6$. The cell experiment was repeated 3 times. Data are presented as mean \pm standard deviation and analyzed using one-way ANOVA, followed by Tukey's multiple comparison test, ${ }^{* *} p<0.01$.

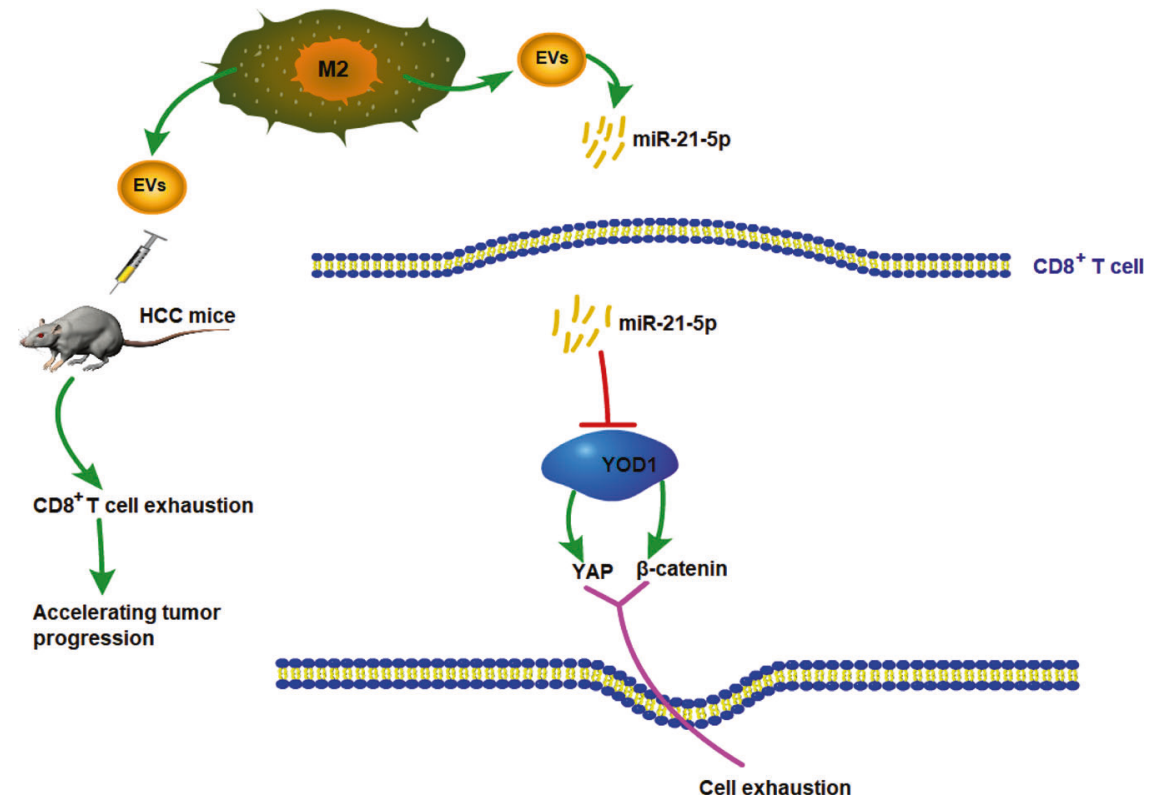

Fig. 8 M2 macrophage-derived EVs promote the depletion of CD8 + T cells in HCC via the miR-21-5p/YOD1/YAP/ $\beta-c a t e n i n$ axis. M2 macrophage-derived EVs carried miR-21-5p into $C D 8^{+}$T cells, inhibited YOD 1 expression, and activated the YAP/ $\beta$-catenin pathway, thereby promoting $\mathrm{CD}^{+} \mathrm{T}$ cell exhaustion in HCC. 
functions as a tumor promoter, but also enhances the immunosuppression of CD4 and CD8 T cells [27]. YAP can typically bind to the TEAD transcription factor, but the binding protein of YAP in immune cells is still unclear. In the future, we will explore the upstream IncRNAs involved in the regulation of $\mathrm{M} 2$ macrophagederived $\mathrm{EVs}$ or the mechanisms of other miRNAs in $\mathrm{CD}^{+}$cell exhaustion in HCC.

\section{DATA AVAILABILITY}

All the data generated or analyzed during this study are included in this published article.

\section{REFERENCES}

1. Liu CY, Chen KF, Chen PJ. Treatment of liver cancer. Cold Spring Harb Perspect Med. 2015;5:a021535.

2. Suh JK, Lee J, Lee JH, Shin S, Tchoe HJ, Kwon JW. Risk factors for developing liver cancer in people with and without liver disease. PLoS ONE. 2018;13:e0206374.

3. Pinato DJ, Guerra N, Fessas P, Murphy R, Mineo T, Mauri FA, et al. Immune-based therapies for hepatocellular carcinoma. Oncogene 2020;39:3620-37.

4. Greten TF, Lai CW, Li G, Staveley-O'Carroll KF. Targeted and immune-based therapies for hepatocellular carcinoma. Gastroenterology 2019;156:510-24.

5. Lu C, Rong D, Zhang B, Zheng W, Wang X, Chen Z, et al. Current perspectives on the immunosuppressive tumor microenvironment in hepatocellular carcinoma: challenges and opportunities. Mol Cancer. 2019;18:130.

6. Huang CY, Wang Y, Luo GY, Han F, Li YQ, Zhou ZG, et al. Relationship between PD-L1 expression and CD8+ T-cell immune responses in hepatocellular carcinoma. J Immunother. 2017;40:323-33.

7. Han ZG. Functional genomic studies: insights into the pathogenesis of liver cancer. Annu Rev Genomics Hum Genet. 2012;13:171-205.

8. Xu F, Jin T, Zhu Y, Dai C. Immune checkpoint therapy in liver cancer. J Exp Clin Cancer Res. 2018;37:110.

9. Zheng C, Zheng L, Yoo JK, Guo H, Zhang Y, Guo X, et al. Landscape of infiltrating T cells in liver cancer revealed by single-cell sequencing. Cell. 2017;169:1342-56. e1316

10. Ma J, Zheng B, Goswami S, Meng L, Zhang D, Cao C, et al. PD1(Hi) CD8(+) T cells correlate with exhausted signature and poor clinical outcome in hepatocellular carcinoma. J Immunother Cancer. 2019;7:331.

11. Wherry EJ, Kurachi M. Molecular and cellular insights into T cell exhaustion. Nat Rev Immunol. 2015;15:486-99.

12. Novikova MV, Khromova NV, Kopnin PB. Components of the hepatocellular carcinoma microenvironment and their role in tumor progression. Biochemistry (Mosc.). 2017;82:861-73.

13. Tahmasebi Birgani M, Carloni V. Tumor microenvironment, a paradigm in hepatocellular carcinoma progression and therapy. Int J Mol Sci. 18; (2017).

14. Murray PJ, Wynn TA. Protective and pathogenic functions of macrophage subsets. Nat Rev Immunol. 2011;11:723-37.

15. Arneth B Tumor Microenvironment. Medicina (Kaunas). 2019;56.

16. $\mathrm{Wu}$ T, Dai $\mathrm{Y}$. Tumor microenvironment and therapeutic response. Cancer Lett. 2017;387:61-68.

17. Capece D, Fischietti M, Verzella D, Gaggiano A, Cicciarelli G, Tessitore A, et al. The inflammatory microenvironment in hepatocellular carcinoma: a pivotal role for tumor-associated macrophages. Biomed Res Int. 2013;2013:187204.

18. Giusti I, Di Francesco M, D'Ascenzo S, Palmerini MG, Macchiarelli G, Carta G, et al. Ovarian cancer-derived extracellular vesicles affect normal human fibroblast behavior. Cancer Biol Ther. 2018;19:722-34.

19. Lan J, Sun L, Xu F, Liu L, Hu F, Song D, et al. M2 macrophage-derived exosomes promote cell migration and invasion in colon cancer. Cancer Res. 2019;79:146-58.

20. Zhang Y, Meng W, Yue P, Li X. M2 macrophage-derived extracellular vesicles promote gastric cancer progression via a microRNA-130b-3p/MLL3/GRHL2 signaling cascade. J. Exp. Clin. Cancer Res. 2020;39:134.

21. Wu L, Xia J, Li D, Kang Y, Fang W, Huang P. Mechanisms of M2 macrophagederived exosomal long non-coding RNA PVT1 in regulating Th17 cell response in experimental autoimmune encephalomyelitisa. Front Immunol. 2020;11:1934.

22. Wu H, Mu X, Liu L, Wu H, Hu X, Chen L, et al. Bone marrow mesenchymal stem cells-derived exosomal microRNA-193a reduces cisplatin resistance of non-small cell lung cancer cells via targeting LRRC1. Cell Death Dis. 2020;11:801.

23. Lou W, Liu J, Ding B, Chen D, Xu L, Ding J, et al. Identification of potential miRNAmRNA regulatory network contributing to pathogenesis of HBV-related HCC. J Transl Med. 2019;17:7.

24. Cui J, Li Q, Luo M, Zhong Z, Zhou S, Jiang L, et al. Leukemia cell-derived microvesicles induce $T$ cell exhaustion via miRNA delivery. Oncoimmunology 2018;7:e1448330.
25. Sehrawat S, Koenig PA, Kirak O, Schlieker C, Fankhauser M, Ploegh HL. A catalytically inactive mutant of the deubiquitylase YOD-1 enhances antigen crosspresentation. Blood. 2013;121:1145-56.

26. Kim Y, Kim W, Song Y, Kim JR, Cho K, Moon H, et al. Deubiquitinase YOD1 potentiates YAP/TAZ activities through enhancing ITCH stability. Proc Natl Acad Sci USA. 2017;114:4691-6.

27. Lebid A, Chung L, Pardoll DM, Pan F. YAP attenuates CD8 T cell-mediated antitumor response. Front Immunol. 2020;11:580.

28. Ruiz de Galarreta M, Bresnahan E, Molina-Sanchez P, Lindblad KE, Maier B, Sia D. et al. Beta-catenin activation promotes immune escape and resistance to anti-PD1 therapy in hepatocellular carcinoma. Cancer Discov.2019;9:1124-41.

29. Tian X, Wu Y, Yang Y, Wang J, Niu M, Gao S, et al. Long noncoding RNA LINC00662 promotes M2 macrophage polarization and hepatocellular carcinoma progression via activating Wnt/beta-catenin signaling. Mol. Oncol. 2020;14:462-83.

30. Yeung OW, Lo CM, Ling CC, Qi X, Geng W, Li CX, et al. Alternatively activated (M2) macrophages promote tumour growth and invasiveness in hepatocellular carcinoma. J. Hepatol. 2015;62:607-16.

31. Li L, Sun P, Zhang C, Li Z, Cui K, Zhou W. MiR-98 modulates macrophage polarization and suppresses the effects of tumor-associated macrophages on promoting invasion and epithelial-mesenchymal transition of hepatocellular carcinoma. Cancer Cell Int. 2018;18:95.

32. Kurachi M. CD8(+) T cell exhaustion. Semin Immunopathol. 2019;41:327-37.

33. Hu W, Song X, Yu H, Sun J, Zhao Y. Released exosomes contribute to the immune modulation of cord blood-derived stem cells. Front Immunol. 2020;11:165.

34. Xu R, Rai A, Chen M, Suwakulsiri W, Greening DW, Simpson RJ. Extracellular vesicles in cancer - implications for future improvements in cancer care. Nat Rev Clin Oncol. 2018;15:617-38.

35. Nagy A, Lanczky A, Menyhart O, Gyorffy B. Validation of miRNA prognostic power in hepatocellular carcinoma using expression data of independent datasets. Sci Rep. 2018;8:9227.

36. Feng $\mathrm{YH}$, Tsao CJ. Emerging role of microRNA-21 in cancer. Biomed Rep 2016;5:395-402.

37. Cao LQ, Yang XW, Chen YB, Zhang DW, Jiang XF, Xue P. Exosomal miR-21 regulates the TETs/PTENp1/PTEN pathway to promote hepatocellular carcinoma growth. Mol Cancer. 2019;18:148.

38. Wang J, Chu Y, Xu M, Zhang X, Zhou Y, Xu M. miR-21 promotes cell migration and invasion of hepatocellular carcinoma by targeting KLF5. Oncol Lett. 2019;17:2221-7.

39. Yang $F$, Wang T, Du P, Fan H, Dong $X$, Guo $H$. M2 bone marrow-derived macrophage-derived exosomes shuffle microRNA-21 to accelerate immune escape of glioma by modulating PEG3. Cancer Cell Int. 2020;20:93.

40. Meng G, Wei J, Wang Y, Qu D, Zhang J. miR-21 regulates immunosuppression mediated by myeloid-derived suppressor cells by impairing RUNX1-YAP interaction in lung cancer. Cancer Cell Int. 2020;20:495.

41. Liu Y, Ye Y. Roles of p97-associated deubiquitinases in protein quality control at the endoplasmic reticulum. Curr. Protein Pept. Sci. 2012;13:436-46.

42. Kim Y, Jho EH. Deubiquitinase YOD1: the potent activator of YAP in hepatomegaly and liver cancer. BMB Rep. 2017;50:281-2.

43. Noguchi $S$, Saito A, Nagase T YAP/TAZ signaling as a molecular link between fibrosis and cancer. Int J Mol Sci. 2018;19.

44. Yuan WC, Pepe-Mooney B, Galli GG, Dill MT, Huang HT, Hao M, et al. NUAK2 is a critical YAP target in liver cancer. Nat. Commun. 2018;9:4834.

45. Vilchez V, Turcios L, Marti F, Gedaly R. Targeting Wnt/beta-catenin pathway in hepatocellular carcinoma treatment. World J Gastroenterol. 2016;22:823-32.

46. Li X, Xiang Y, Li F, Yin C, Li B, Ke X. WNT/beta-Catenin signaling pathway regulating $\mathrm{T}$ cell-inflammation in the tumor microenvironment. Front Immunol. 2019;10:2293.

47. Fitamant J, Kottakis F, Benhamouche S, Tian HS, Chuvin N, Parachoniak CA, et al. YAP inhibition restores hepatocyte differentiation in advanced HCC, leading to tumor regression. Cell Rep. 2015;10:1692-707.

\section{ACKNOWLEDGEMENTS}

This study was supported by Baise Scientific Research and Technology Planning Bureau (Grant No.BK20204723) and Guangxi Natural Science Foundation of China (Grant No.2019GXNSFBA245023 and Grant No.2020GXNSFAA259019). The funding body didn't participate in the design of the study and collection, analysis, and interpretation of data and in writing the manuscript.

\section{AUTHOR CONTRIBUTIONS}

JP and ZMX are the guarantors of the integrity of the entire study; JP and ZMX contributed to the study concepts, study design, the definition of intellectual content, literature research, manuscript preparation, and manuscript editing and review; JHN contributed to the definition of intellectual content; QF and MY contributed to the 
14

literature research; YGH contributed to the experimental studies; WCL, BG, and JCW contributed to the data analysis, statistical analysis, and manuscript editing and review; HMW contributed to the data acquisition and literature research, manuscript preparation. All authors read and approved the final manuscript.

\section{CONFLICT OF INTEREST}

The authors declare no conflicts of interest.

\section{ETHICS STATEMENT}

This study was approved by the Ethical Committee of Affiliated Hospital of Youjiang Medical College for Nationalities. Adequate laboratory procedures were made to minimize the pain of mice, such as heating pads, disinfection, and fluid replacement with normal saline.

\section{ADDITIONAL INFORMATION}

Supplementary information The online version contains supplementary material available at https://doi.org/10.1038/s41420-021-00556-3.

Correspondence and requests for materials should be addressed to H.W.
Reprints and permission information is available at http://www.nature.com/ reprints

Publisher's note Springer Nature remains neutral with regard to jurisdictional claims in published maps and institutional affiliations.

Open Access This article is licensed under a Creative Commons Attribution 4.0 International License, which permits use, sharing, adaptation, distribution and reproduction in any medium or format, as long as you give appropriate credit to the original author(s) and the source, provide a link to the Creative Commons license, and indicate if changes were made. The images or other third party material in this article are included in the article's Creative Commons license, unless indicated otherwise in a credit line to the material. If material is not included in the article's Creative Commons license and your intended use is not permitted by statutory regulation or exceeds the permitted use, you will need to obtain permission directly from the copyright holder. To view a copy of this license, visit http://creativecommons. org/licenses/by/4.0/.

(c) The Author(s) 2021 